PACS File \#2700

\title{
Interpreting Economic Time Series
}

Thomas J. Sargent

April 1980

Staff Report \#58

\author{
University of Minnesota \\ and
}

Federal Reserve Bank of Minneapolis

This paper explores some of the implications for econometric practice of the principle that people's observed behavior will change when their constraints change. In dynamic contexts, a proper definition of people's constraints includes among them laws of motion that describe the evolution of the taxes they must pay and the prices of the goods that they buy and sell. Changes in agents' perceptions of these laws of motion (or constraints) will in general produce changes in the schedules that describe the choices they make as a function of the information that they possess. Until very recently, received dynamic econometric practice ignored this principle. The practice of dynamic econometrics should be changed so that it is consistent with the principle that people's rules of choice are influenced by their constraints. This is a substantial undertaking, and involves major adjustments in the ways that we formulate, estimate, and simulate econometric models.

The views expressed herein are solely those of the author and do not necessarily represent the views of the Federal Reserve Bank of Minneapolis or the Federal Reserve System.

Note: Many of my thoughts on the subject of this paper have been heavily influenced by numerous discussions with Lars Peter Hansen and Robert E. Lucas, Jr. The observations on Bayesian methods are in large part those of Hansen. Ian Bain made many helpful comments on an earlier draft. 


\section{Introduction}

This paper explores some of the implications for econometric practice of a single principle from economic theory. This principle is that people's observed behavior will change when their constraints change. In dynamic contexts, a proper definition of people's constraints includes among them laws of motion that describe the evolution of the taxes they must pay and the prices of the goods that they buy and sell. Changes in agents' perceptions of these laws of motion (or constraints) will in general produce changes in the schedules that describe the choices they make as a function of the information that they possess. Until very recently, received dynamic econometric practice ignored this principle, and routinely deduced policy conclusions by assuming that people's rules of choice would not vary, for example, with the government's choices of laws of motions for variables such as tax rates, goverament purchases and so on. These variables are supposed to have their effects precisely because they influence the constraints of some private agents.

The practice of dynamic econometrics should be changed so that it is consistent with the principle that people's rules of choice are influenced by their constraints. This is a substantial uncertaking, and involves major adjustments in the ways that we formulate, estimate, and simulate econometric models. Foremost, we need a stricter definition of the class of parameters that can be regarded as "structural". The body of doctrine associated with the "simultaneous equations" model in econometrics properly directs the attention of the researcher beyond reduced form parameters to the parameters of "structural equations" which presumably describe those aspects of the behavior of people that prevail 
across a range of hypothetical environments. Estimates of the parameters of structural equations are needed in order to analyze an interesting class of policy interventions. Most often, however, included in a prominent way among the "structural equations" have been equations describing the rules of choice for private agents. Consumption functions, investment schedules, demand functions for assets, and agricultural supply functions are all examples of such rules of choice. In dynamic settings, regarding the parameters of these rules of choice as structural or invariant under interventions violates our simple principle from economic theory.

This paper describes methods for interpreting economic time series in a manner consistent with the principle that people's constraints influence their behavior. For the most part, I shall restrict things so that the dynamic economic theory is of the equilibrium variety, with optimizing agents and cleared markets. Eowever, many of the principles described here will pertain to other types of dynamic economic theories, such as "disequilibrium" models with optimizing agents. The line of work I shall describe has diverse antecedents, of which major ones are contributions of Muth [46, 47], Lucas [33, 34], Lucas and Prescott [37], Nerlove [50], and Graves and Telser [17]. 1 / The works of Granger [16] and Sims [57] have provided key technical econometric foundations.

The basic idea is to interpret a collection of economic time series as resulting from the choices of private agents interacting in markets assumed to be organized along well specified Iines. The private agents are assumed to face nontrivial dynamic and stochastic optimization problems. This is an attractive assumption because the solutions of such problems are known to imply that the chosen variables (e.g. stocks of factors of production or financial assets) can exhibit serial correlation and cross-serial correlation. Since 
time series of economic data usually have the properties of high own-serial correlation and various patterns of cross-serial correlation, it seems that there is potential for specifying dynamic preferences, technologies, constraints and rules of the market game that roughly reproduce the serial correlation and cross-correlation patterns in a given collection of time series measuring market outcomes. If this can be done in such a fashion that the free parameters of preferences, technologies, and constraints are identifiable econometrically, it is then possible to interpret the collection of time series as the outcome of a well specified dynamic, stochastic equilibrium model. This paper is intended as a nontechnical summary of some of the econometric and theoretical issues involved in interpreting data in this way.

But why should anybody want to interpret time series data as representing the results of interactions of private agents' optimizing choices? The answer is not that this way of modeling is aesthetically pleasing, although it is, nor that modeling in this way guarantees an analysis that implies no role for government intervention, which it doesn't. The reason for interpreting time series in this way is practical: it potentially offers the analyst the ability to predict how agents' behavior and the random behavior of mariket-determined variables will each change when there are policy interventions or other changes in the environment that alter some of the agents' dynamic constraints. There is a general presumption that private agents' behavior and the randoll behavior of rarket outcomes both will change whenever agents' constraints change, as when policy interventions or other changes in the environment occur. The most that can be hoped for is that the parameters of agents' preferences and technologies will not change in the 
face of such changes in the environment. If the dynamic econometric model is formulated explictly in terms of the parameters of preferences, technologies and constraints, it will in principle be possible for the analyst to predict the effects on observed behavior of changes in the stochastic environment.

Past dyamic econometric studles should usually be regarded as having been directed at providing ways of summarizing the observed behavior of interrelated variables, without attempting to infer the objectives, opportunities, and constraints of the agents whose decisions determine those variables. Most existing studies can be viewed, at best, as having estimated parameters of agents' decision rules for setting chosen variables as functions of the information they possess. Most of the better studies of consumption, investment, asset demand, and agricultural supply functions must be interpreted as having estimated such decision rules. Dynamic economic theory implies that these decision rules cannot be expected to remain invariant in the face of policy interventions that take the form of changes in some of the constraints facing agents. This means that there is a theoretical presumption that historical econometric estimates of such decision rules w1l provide poor predictions about behavior in a hypothetically new environment. This was Robert E. Lucas's [34] critique of econometric policy evaluation procedures as tirey existed in 1973.

Some readers of Lucas [34] have Interpreted the message as a call to evaluate policies by using existing econometric models differently. $\underline{\text { / } /}$ However, one implication of Lucas's argument, and of dynamic economic theory generally, is that the formulation, identification, and estimation of the models much each be approached in substantially new and different ways. Most existing models simply cannot be saved by simulating them a little more shrewdiy. $\frac{3}{\prime}$ 
Formulating and estimating "rational expectations" models and dynamic equilibrtum models of economic time series involves a varlety of important conceptual and econometric issues, some of which I try to sumarize in this paper. Among the issues to be treated are the following:

(1) Identification criteria. Prior identlfying information of the Cowles commission variety, i.e., mainly exclusion restrictions, play a much smaller role in dynamic equilibrium models. Nonlinear cross-equation restrictions implied by dynamic theory are used extensively. This shift involves impcrtant modifications of past ways of thinking about identification and estimation.

(ii) Models of error terms. The dynamic equilibrium modeling strategy virtually forces the researcher to think about the sources and interpretations of the error terms in the stochastic equations that he fits. The explicitly stochastic nature of the theorizing makes it difficult to "tack on" error terms after the theorizing is done, a usual procedure in the past.

(iii) The role of Granger-causality. Granger causality turns out to be a critical concept in the formulation of dynamic economic models, as it is coincident with the condition for the appearance as an information variable in an agent's decision rule of a variable not otherwise in the agent's criterion function or constraints.

(iv). Bayesian analysis: Bayesian econonetric teciniques : ruvide a means of mixing prior theoretical information about parameters with information from the data. Such procedures are widely used by applied time series econometriclans, although often no formal Bayesian justification is given. Dynamic economic theory provides no justification for one widely imposed class of prior restrictions which can be viewed as restrictions directly on decision rules. Instead, dynamic economic theory suggests that prior information about agents' criterion functions 
and constraints is what should be used in estimation. This feature of dynamic economic theory has implications for the proper implementation both of formal Bayesian procedures and of less formal procedures for constraining parameter estimates.

I shall organize my discussion around a pair of examples. In section I, I describe a linear-quadratic version of Lucas and Prescott's model of investment under uncertainty. I shall use this example for discussing the econometric implications of dynamic equilibrium models. In section 2, I describe a very simple model of interrelated corn and hog markets. Though it is overly simple, this model illustrates how many of the points addressed in section 1 generalize, and also illustrates what I believe to be some essential principles that would be involved in building a useful econometric model of the "corn-hog cycle". In the Lucas-Prescott example, state variables which help the firm predict the future prices of inputs appear in the representative firm's decision rule. However, the laws of motion of these input prices are taken as given from outside the model. In actuality, the prices of these inputs are usually thought to be determined by trades in "another" market, one source of demand for which stems from the industry being modeled by Lucas and Prescott. What modifications to the analysis occur if this "other" market is modeled explicitly? The corn-hog example is designed to study this question. The corn-hog model goes beyond the Lucas-Prescott example by permitting the output of one industry, corn, to be an input into the production of the other industry, hogs. Since hog producers have an incentive to forecast future corn prices, it follows that "state variables" that appear in the laws of motion for the total output and price of corn appear in the decision rule of the representative hog producer. Also, because the corn producer has an incentive to forecast the price of corn, 
which depends partly on the demand for corn from hog producers, the "state variables" that appear in the laws of motion for the total hog output and the price of hogs appear in the optimal decision rule of the representative corn producer. Hence, each industry inherits the state variables of the other. Further, the equilibria in the two industries are inextricably interrelated. The corn-hog example illustrates an important general phenomenon: that rational expectations equilibria of industries that are related only because they trade with one another technically become equivalent to the solution of "interrelated factor demand" problems in which quantities and prices for different goods interact pervasively.

I have adopted linear-quadratic setups because they simplify both the theoretical and econometric discussions, while illustrating many of the salient methodological implications of dynamic decision theory. Iinear-quadratic optimum problems deliver difference equations that are linear in the variables, and so match up nicely with much existing dynamic econometric theory. The reader familiar with lucas and Prescott [37] will recognize how the corn-hog model of section 2 can be generalized to incorporate more general specifications for the technologies, preferences, and constraints. That increased generality would make the econometric implications harder to extract than with the present setup, without altering the basic message. 4 / 
1. Investment Under Uncertainty

This section describes a Iinear-quadratic version of Lucas and Prescott's model of investment, and uses it as a vehicle for expositing a variety of conceptual and econometric issues. The model describes the mutual determination over time of the capital stock, output, and market price of a single industry. The model can be generalized to handle multiple factors of production, at the cost of what are really only technical complications. In section 2 , I indicate how the model can be extended to analyze two or more interdependent industries, such as the "hog and corn" industries. Finally, I mention that it is straightforward to modify the model to incorporate much richer dynamics by generalizing the nature of the adjustment costs.

I define the following variables:

$y_{t}=$ output of the representative firm

I = number of firms in the industry, assumed constant over time

$Y_{t}=n y_{t}=$ total output of industry

$P_{t}=$ price of output

$D_{1 t}=a\left(p_{1} \times 1\right)$ vector of random variables appearing in the industry demand schedule, $P_{1} \geq 1$

$D_{2 t}=a\left(p-p_{1}\right) \times I$ vector of random variables which help predict future values of the collection of variables $D_{1 t}, P \geq P_{I}$

$D_{t}=\left[D_{2 t}^{D_{1 t}}\right]$

$w_{t}=$ rental rate on capital

$W_{t}=a(q \times 1)$ vector whose first element is $w_{t}$; the remaining elements of $w_{t}$ are variables that help predict future $w_{t}$ 's. 
$u_{t}=a$ random shock to demand

$\epsilon_{t}=$ a randon shock in the production function

$k_{t}=$ stock of capital of the representative firm

$\mathrm{K}_{t}=n k_{t}=$ total capital stock in industry

The subscript $t$ indexes the date to which the variable corresponds.

I further define the following polynomials in the lag operator

L:

$\delta_{u}(L)=1-\sum_{j=1}^{r_{u}} \delta_{u j} I^{j}$, where $\delta_{u j}$ is a scalar

$\delta_{D}(L)=I_{P}-\sum_{j=I}^{I_{D}} \delta_{D_{j}} I^{j}$, where $\delta_{D j}$ is a $p \times p$ matrix and $I_{p}$ is the $\delta_{w}(I)=I_{q}-\sum_{j=1}^{I_{w}} \varepsilon_{w j} I^{j}$, where $\delta_{w j}$ is a $(q \times q)$ matrix and $I_{q}$ is the $\delta_{\varepsilon}(L)=1-\sum_{j=1}^{\mathfrak{r} \varepsilon} \delta_{\varepsilon j} I^{j}$, where $\delta_{\varepsilon j}$ is a scalar. $\underline{5}$

The industry consists of $n$ identical competitive firms, each of which uses a single factor of production, capital, to produce a single output. Output of the representative firm $y_{t}$ is governed by

$$
y_{t}=E k_{t}+n^{-1} \varepsilon_{t}, \quad f>0
$$

where $k_{t}$ is the representative firm's stock of capital at $t$, and $\varepsilon_{t}$ is a random error in the technology. The firm knows $\left\{\varepsilon_{t}, \varepsilon_{t-1}, \ldots\right\}$, but does not know with certainty future values of the shock $\varepsilon_{t}$. The error $\varepsilon_{t}$ is known to follow the $r_{\varepsilon}^{-t h}$ order Markov process

$$
\delta_{\varepsilon}(L) \varepsilon_{t}=V_{t}^{\varepsilon}
$$


where $v_{t}^{\varepsilon}$ is a "fundamental" white noise error term for $\varepsilon_{t} .6 /$ The firm is assumed to know $\delta_{\varepsilon}(L)$ and $E\left(V_{t}^{\varepsilon}\right)^{2}$ with certainty. The demand curve for output is given by

$$
P_{t}=A_{0}-A_{1} Y_{t}+A_{2} D_{1 t}+u_{t} \quad A_{0}, A_{1}>0
$$

where $D_{1 t}$ is a $\left(P_{1} \times 1\right)$ vector of "demand shifters", $A_{2}$ is a $\left(1 \times p_{1}\right)$ vector of constants, and $u_{t}$ is a randon shock to the demand curve. The random term $u_{t}$ obeys the $I_{u}^{\text {th }}$ order Markov process

$$
(1.4) \quad \hat{o}_{u}(I) u_{t}=v_{t}^{u}
$$

where $V_{t}^{u}$ is a fundamental white noise for $u_{t}$. The $\left(p_{1} \times 1\right)$ vector of demand shifters $D_{1 t}$ consists of the first $p_{1}$ rows of the $p \times 1$ vector $D_{t}$, which follows the $I_{D}{ }^{t h}$ order vector autoregressive process

$$
\delta_{D}(I) D_{t}=V_{t}^{D}
$$

where $v_{t}^{D}$ is a $(p \times 1)$ vector white noise that is fundamental for the process $D_{t}$. The representative firm is assumed to know $\delta_{u}(L), \delta_{D}(L), A_{0}, A_{1}, A_{2}$, and the second moments of $\nabla_{t}^{U}$ and $\nabla_{t}^{D}$ with certainty.

At time $t$, total output is given by

$$
Y_{t}=n g_{t}=f R_{t}+\varepsilon_{t}
$$

The representative firm's problem is to choose a contingency plan for $k_{t+j}$ to maximize the criterion 


$$
E_{0} \sum_{t=0}^{\infty} B^{t}\left\{P_{t} y_{t}-w_{t} k_{t}-\frac{d}{2}\left(k_{t+1}-k_{t}\right)^{2}\right\}
$$

subject to $k_{0}$ given. In (7), $E_{t}$ is the mathematical expectation operator, conditional on information known to the firm at time $t$. This information set will shortly be specified precisely. In (7), d is a positive constant. The term $\frac{d}{2}\left(k_{t+1}-k_{t}\right)^{2}$ is intended to represent the notion that there are costs internal to firm of adjusting the capital stock, and that these rise at an increasing rate with the absolute value of the change in capital. We assume that the rental on capital $w_{t}$ is the first element of the $(q \times 1)$ vector random process $W_{t}$ that obeys the $r_{W}^{t h}$ order vector autoregression

$$
\delta_{w}(I) W_{t}=V_{t}^{W}
$$

where $\nabla_{t}^{W}$ is a $(q \times 1)$ vector white roise that is fundamental for $W_{t}$. The firm is supposed to know $\hat{o}_{w}(I)$ and the second moment matrix of $V_{t}^{W}$ with certainty.

At time, $t$, the firm chooses $k_{t+1}$, given the information that it has available at $t$. However, the maximization problem (7) is not yet well posed, since we have not completely spelled out the dynamic constraints with respect to which the maximization is supposed to occur. To complete the problem (7), we begin by substituting $\left(f k_{t}+n^{-1} \varepsilon_{t}\right)$ for $y_{t}$, and $\left[A_{0}-A_{1} \neq R_{t}-A_{1} \varepsilon_{t}+A_{2} D_{I t}+a_{t}\right]$ for $P_{t}$ to get

$$
\begin{gathered}
E_{0} \sum_{t=0}^{\infty} B^{t}\left\{\left[A_{0}-A_{I} f K_{t}-A_{1} \varepsilon_{t}+A_{2} D_{1 t}+u_{t}\right]\left[f k_{t}+n^{-1} \varepsilon_{t}\right]\right. \\
\left.-w_{t} k_{t}-\frac{d}{2}\left(k_{t+1}-k_{t}\right)^{2}\right\} .
\end{gathered}
$$


In order that the problem of maximizing (9) with respect to a contingency plan for $\left\{k_{t+j}\right\}$ be well posed, it is necessary to attribute to the firm precise views about the laws of motion of the random variables that it cannot control, but whose values influence the best choice of its own stocks of capital. For problem (9), these "uncontrollable" variables about which the representative firm cares are $k_{t}, D_{1 t}, u_{t}$ and $w_{t}$. The firm cares about the present and future behavior of the variables $\left(k_{t}, D_{1 t}, u_{t}\right)$ because they influence the present and future behavior of the market price through the demand relationship $P_{t}=A_{0}-A_{1} f R_{t}+A_{2} D_{1 t}+u_{t}$. The firm cares about the evolution of the rental process $w_{t}$ because it influences its costs. We have already completely described our assumptions about the firm's views of the laws of motion of $D_{I t}$, $u_{t}$ and $w_{t}$ ' namely, that the firm knows the Markov laws (4), (5), and (8) that govern them, and at time $t$ knows $D_{t}, D_{t-1}, \ldots, u_{t}, u_{t-1}, \ldots$, and $W_{t}$, $W_{t-I}, \ldots,$. To complete the specification Iequires that we specify the Eirm's views about the evolution of the aggregate capital stock $\mathrm{R}_{t}$. We assume that the representative firm believes that the aggregate capital stock evolves according to the law

$$
\begin{aligned}
K_{t+I}=H_{0} & +H_{w}(I) W_{t}+H_{D}(I) D_{t}+H_{\varepsilon}(I) \varepsilon_{t} \\
& +H_{u}(I) u_{t}+H_{I} K_{t}
\end{aligned}
$$

where $\mathrm{H}_{0}$ and $\mathrm{H}_{1}$ are scalars and

$$
\begin{aligned}
& H_{w}(I)=\sum_{j=0}^{I_{w}^{-I}} H_{w j} I^{j} \text {, where } B_{w j} \text { is }(I \times q) \\
& H_{D}(I)=\sum_{j=0}^{I_{D}^{-I}} H_{D j} I^{j} \text {, where } H_{D j} \text { is }(I \times p)
\end{aligned}
$$




$$
\begin{aligned}
& H_{\varepsilon}(I)=\sum_{j=0}^{I} H_{\varepsilon j}^{-1} I^{j} \text {, where } B_{\varepsilon j} \text { is a scalar } \\
& H_{u}(I)=\sum_{j=0}^{r} H_{u j} I^{j} \text {, where } H_{u j} \text { is a scalar. }
\end{aligned}
$$

The representative firm is assumed to know all of the parameters of the linear law of motion (10) with certainty. The reason that we have chosen the form (10) as the firm's perceived law of motion for $K$ will shortly become apparent.

With these specifications, the maximization of $(9)$ is now well posed. Sumarizing the setup, we have that the representative firm maximizes

$$
\begin{gathered}
E_{0} \sum_{t=0}^{\infty} B^{t}\left\{\left[A_{0}-A_{1} f R_{t}-A_{1} \varepsilon_{t}+A_{2} D_{1 t}+u_{t}\right]\left[f k_{t}+{ }^{-1} \varepsilon_{t}\right]\right. \\
\left.-w_{t} k_{t}-\frac{d}{2}\left(k_{t+1}-k_{t}\right)^{2}\right\}
\end{gathered}
$$

subject to the laws of motion 8 /

$$
\begin{aligned}
k_{t+I}= & H_{0}+H_{w}(I) W_{t}+H_{D}(L) D_{t}+H_{\varepsilon}(L) \varepsilon_{t} \\
& +H_{u}(L) u_{t}+H_{I} K_{t}
\end{aligned}
$$

$$
\delta_{w}(I) w_{t}=v_{t}^{w}
$$

$$
\delta_{u}(I) u_{t}=v_{t}^{u}
$$

$$
\delta_{D}(I) D_{t}=V_{t}^{D}
$$

$$
\delta_{\varepsilon}(\mathrm{I}) \varepsilon_{t}=v_{t}^{\varepsilon}
$$


and subject to the information set at time $t, \underline{9}$

$$
\begin{gathered}
\left\{k_{t}, k_{t}, w_{t}, W_{t-I}, \ldots, W_{t-I}+I, D_{t}, D_{t-I}, \ldots, D_{t-I_{D}+I},\right. \\
\left.\varepsilon_{t}, \varepsilon_{t-1}, \ldots, \varepsilon_{t-r}+I, u_{t}, u_{t-1}, \ldots, u_{t-I_{u}+1}\right\} .
\end{gathered}
$$

Iive izirin maximizes (9) taking the laws of motion $(\varepsilon),(4),(5),(2)$ and (10) as given and beyond its control. The firm is assumed to behave competitiveiy and to act as if it has no control over the aggregate capital stock $K$. This is a reasonable assumption if $n$ is large. The firm is assumed to know the $\delta^{\prime} s$ and $H^{2} s$ with certainty, and to know the first and second moments of the $v_{t}^{\prime} s . \frac{10 /}{}$ We further restrict the problem so that the solution is a linear contingency plan.11/ For this to be true, it is sufficient that the least squares predictors of future $W, D, \varepsilon$, and $u$ 's be linear in the conditioning variables. This will be true if $v_{t}^{E}, v_{t}^{v}, v_{t}^{D}$, and $v_{t}^{W}$ obey normal probability laws. Alternstively, the analyst can simply assume that the industry is operating under optimal linear rules. $\therefore$ either cage, the sulution of the renresentative Eiru's prubia: ic = indar contingency pan of the form in!

$$
\begin{aligned}
k_{t+1}=h_{0} & +h_{w}(L) w_{t}+h_{D}(I) D_{t}+h_{\varepsilon}(I) \varepsilon_{t} \\
& +h_{u}(I) u_{t}+h_{1} k_{t}+h_{2} k_{t}
\end{aligned}
$$

where $h_{0}, h_{1}$, and $h_{2}$ are scalars, and

$$
\begin{aligned}
& I_{w}-1 \\
& h_{w}(I)=\sum_{j=0}^{w} h_{w j} I^{j} \text {, where } h_{w j} \text { is }(I \times q) \\
& h_{D}(I)=\sum_{j=0}^{I_{D}-I} h_{D j} I^{j} \text {, where } h_{D j} \text { is }(I \times D) \\
& h_{\varepsilon}(I)=\sum_{j=0}^{I_{\varepsilon}-I} h_{\varepsilon j} I^{j} \text {, where } h_{\varepsilon j} \text { is a scalar } \\
& h_{u}(L)=\sum_{j=0}^{r} h_{u j} I^{j} \text {, where } h_{u j} \text { is a scalar. }
\end{aligned}
$$


The h's of (11) are in general functions both of the parameters in the criterion function (9), the parameters of $\delta_{\mathrm{w}}, \delta_{\mathrm{u}}, \delta_{\mathrm{D}}$, and $\delta_{\varepsilon}$ appearing in (8), (4), (5), and (2), and the $H^{\prime} s$ of the perceived law of motion for capital (10). The mapping giving the $h^{\prime}$ s as functions of these other parameters is defined implicitly by standard formulas in linear optimal control theory, as exposited for example by Bertseleas [ 3] and Kwakernaak and Sivan [29]. For present purposes, it is enough to note the existence of this mapping without exploring its nature in detail. The economic content of the mapping from the ' $\delta$ 's, E's and objective function parameters to the $h$ parameters of the firm's decision rule is easy to understand, since it captures the notion that the firm's rule of choice depends both on its objective and its perceived constraints (10), (8), (4), (5) and (2).

Matiplying both sides of the firm's decision rule (11) by a and using $k_{t}=n k_{t}$ gives

$$
\begin{aligned}
K_{t+I} & =n h_{0}+n h_{w}(I) w_{t}+n h_{D}(I) D_{t}+n h_{\varepsilon}(I) \varepsilon_{t} \\
& +n h_{u}(I) u_{t}+\left(n h_{1}+h_{2}\right) R_{t} .
\end{aligned}
$$

Eruation (12) is the actual law of motion for aggregate cagitsi tha: results from the behavior of the representative firm. The representative firm's optimization problem in effect induces a mapping from the firm's perceived law of motion for aggregate capital (10) to the actual law of motion (12). For each possible particular perceived law of motion of the form (10), there is an implied actual law of motion for aggregate capital of the form (12). The notion of rational expectations is that the representative firm's perceptions of (10) are correct. In effect, a rational expectations equilibrium is a fixed point of the mapping that 
the representative firm's optimization problem induces from (10) to (12). Formally, we define a rational expectations equilibrium as a perceived law of motion (10) and an implied actual law of motion (12) which are identically equal. In a rational expectations equilibrium, firms' perceptions about the law of motion for aggregate capital turn out to be confirmed by the aggregate of the choices made by firms. Upon comparing (10) with (12) it is evident that necessary and sufficient conditions for a rational expectations equilibrium are

$$
\begin{aligned}
& H_{0}=n h_{O} \\
& H_{w}(I)=\operatorname{mh}_{w}(I) \\
& H_{D}(I)=n h_{D}(I) \\
& H_{E}(I)=n h_{E}(I) \\
& H_{u}(I)=n h_{u}(I) \\
& H_{I}=\left(n h_{I}+h_{2}\right)
\end{aligned}
$$

Inplicit in the above definition of a rational expectations equilibrium are the following elements: (a) market clearing, (b) optimization of the firm's expected present value, and (c) correct perceptions on the part of firms of the laws of motion of variables affecting their present value but beyond their control.

We begin our analysis of the model by briefly describing aspects of the optimization problem solved by the firm. Among the firstorder necessary conditions for the maximization of $(9)$ is the following system of stochastic "Euler equations", which are derived by 
differentiating ( 9 ) with Iespect to $k_{t}$ for $t=1,2, \ldots$;

$$
\begin{aligned}
& \text { Bak } k_{t+1}-d(1+B) k_{t}+d k_{t-1}=A w_{t} \\
& -\operatorname{de}\left[A_{0}-A_{1} f R_{t}-A_{1} \varepsilon_{t}+A_{2} D_{1 t}+u_{t}\right]
\end{aligned}
$$

or

$$
k_{t+1}-\left(\frac{I}{B}+1\right) k_{t}+\frac{1}{\beta} k_{t-1}=\frac{1}{d} w_{t}-\frac{f}{d} P_{t}
$$

In addition to the system of Euler equations, a transversality condition is among the first order necessary conditions. The transversality condition can be derived by methods described in Sargent [54]. The transversality condition for the present problem in effect requires that the solution possess the property $\lim _{j \rightarrow \infty} E_{t} \beta^{t+j} k_{t+j}=0$.

Using the lag operator, the preceding Euler equation can be rewritten as $13 /$

$$
\left(I-\left(\frac{I}{B}+I\right) I+\frac{1}{\beta} L^{2}\right) k_{t+1}=\frac{1}{d} w_{t}-\frac{E}{d} P_{t}
$$

Using the factorization

$$
\left(I-\left(\frac{I}{B}+I\right) I+\frac{I}{B} I^{2}\right)=\left(I-\frac{I}{B} I\right)(I-I),
$$

the above Euler equation can be written as

$$
\left(I-\frac{I}{B} I\right)(I-L) k_{t+I}=\frac{I}{d} w_{t}-\frac{f}{d} P_{t}
$$

Noting that $\left(I-\frac{I}{\beta} I\right)=-\beta^{-1} L\left(1-\beta L^{-1}\right)$ and operating on both sides of the above equation with $\left[-\dot{\beta}^{-1} L\left(1-B I^{-1}\right)\right]^{-1}$ gives the solution ${ }^{14}$

$$
(I-L) k_{t+1}=\frac{-d^{-I} \beta L^{-1}}{1-\beta L^{-1}} w_{t}+\frac{\beta f d^{-1} L^{-1}}{1-\beta L^{-I}} P_{t}
$$

or equivalently 


$$
(1-I) k_{t+1}=-d^{-1} B \sum_{i=0}^{\infty} \beta^{i} w_{t+i+1}+\beta E d^{-1} \sum_{i=0}^{\infty} \beta^{i} P_{t+i+1}
$$

It can be verified that (14) satisfies both the Euler equations and the transversality condition. Equation (14) would give the appropriate rule for setting $k_{t+1}$ if the firm had perfect foresight about the entire future paths of the rental $w_{t}$ and the output price $P_{t} \cdot$ When the firm does not have perfect foresight, the correct decision rule can be derived by replacing the future values on the right side of (14) with the corresponding mathematical expectations conditional on information the firm does have. This leads to the decision rule 15 ,

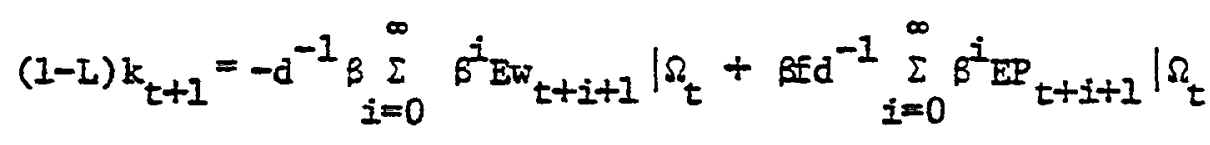

Here $\Omega_{t}$ is defined as the information set $\Omega_{t}=\left\{W_{t}, W_{t-I}, \ldots\right.$, $\left.u_{t}, v_{t-1}, \ldots, D_{t}, D_{t-I}, \ldots, \varepsilon_{t}, \varepsilon_{t-1}, \ldots, R_{t}\right\}$. The conditional mathematical expectations are assumed to be computed using the laws of motion (10), (8), (4), (5), and (2) for $K, W, u, D$, and $\varepsilon$, respectively, as well as the demand relationship $P_{t}=A_{0}-A_{1}\left(f K_{t}+\varepsilon_{t}\right)+A_{2} D_{1 t}+v_{t}$, which is used to deduce the law of motion for $P_{t} \cdot$ Once these conditional mathematical expectations are explicitly calculated in terms of the parameters of (10), (8), (4), (5), (2), and the demand curve (3), they can be substituted into equation (15) to deduce the optimum decision rule (11) for the representative firm. The decision rule (II) is linear in all of the "information variables" that appear on the right side. However, as the above method of calculating the parameters $b$ of the decision rule (II) suggests, the parameters $h$ are themselves complicated nonlinear functions of the underiying parameters of the model: the parameters $A_{0}, A_{1}, A_{2}$ of the demand curve, the parameters $f$ and $d$ 
of the technology; and the parameters $\delta_{u}(L), \delta_{\varepsilon}(I), \delta_{w}(L)$, and $\delta_{D}(I)$ of the laws of motion of the random processes given from outside the model. 16 The $h^{\prime} s$ are also nonlinear functions of the H's of the law of motion of aggregate capital (10), which are not given from outside but are to be determined from the analysis. The nature of these nonlinearities has been characterized by Hansen and Sargent [23], and will be alluded to further below.

Equation (15), which was derived by purely formal manipulations, has the virtue of indicating clearly that the firm has an incentive to forecast future realizations of the rental $w$ and the output price $P$. As a result, any state variables that the firm sees at $t$, and that help predict either future $P^{\prime} s$ or future $w^{\prime} s$, will appear in the firm's decision rule for $k_{t+1}$, given by equation (II). That the h's of (11) are nonlinear functions of the parameters $\left\{A_{0}, A_{1}, A_{2}, f, d, B, \delta_{u}, \delta_{\varepsilon}, \delta_{w}, \delta_{D}, H_{u}, H_{\varepsilon}, H_{w}, E_{D}, H_{0}\right.$ and $\left.H_{1}\right\}$, stems from the nonlinear way in which the conditional mathematical expectations of future $w^{\prime} s$ and $P^{\prime} s$ are functions of these parameters. In practice, to compute a rational expectations equilibrium it is not necessary ever to calculate the right side of (I5). Indeed, it is never necessary explicitly to calculate the h's that determine the decision rule (11) of the representative firm. Instead, the $E^{\prime}$ s of the equilibrium law of motion for the industry can be calculated directly as follows. $17 /$ First, wultiply both sides of equation (13) by $n$, then use $\mathrm{K}_{t}=\mathrm{nk} \mathrm{k}_{\mathrm{t}}$, and collect all terms in $\mathrm{K}$ on the left sicie to get

$$
\begin{aligned}
B d K_{t+1} & -\left[d(1+B)+A_{1} f^{2} B n\right] K_{t}+d K_{t-1}=B \pi w_{t} \\
& -B \pi f A_{0}+A_{1} B f n \varepsilon_{t}-B f n A_{2} D_{1 t}-B f \pi w_{t}
\end{aligned}
$$


It is of some interest that (16) is itself the Euler equation for the "social planning" problem of maximizing $18 /$

$$
\begin{gathered}
E_{0} \sum_{t=0}^{\infty} \beta^{t}\left[\left\{A_{0}\left(f K_{t}+\varepsilon_{t}\right)-\frac{1}{2} A_{1}\left(f K_{t}+\varepsilon_{t}\right)^{2}+\left[f R_{t}+\varepsilon_{t}\right] A_{2} D_{1 t}\right.\right. \\
\left.\left.\quad+\left[f R_{t}+\varepsilon_{t}\right] u_{t}\right\}-w_{t} R_{t}-\frac{1}{2} n^{-1} d\left(R_{t+1}-R_{t}\right)^{2}\right]
\end{gathered}
$$

subject to the laws of motion (8), (4), (5), and (2) for $w_{t}$, ' $t$ ' $D_{I t}$, and $\varepsilon_{t}, \frac{19 /}{}$ and subject to $\mathrm{K}_{0}$ given.

The term in braces is the area under the demand curve, since

$$
\begin{aligned}
& Y_{t}\left[A_{0}-A_{1} x+A_{2} D_{1 t}+u_{t}\right] d x \\
& \quad=A_{0} Y_{t}-\frac{1}{2} A_{1} Y_{t}^{2}+Y_{t} A_{2} D_{1 t}+Y_{t} u_{t} .
\end{aligned}
$$

Thus (IT) is the discounted area under the demand curve minus the total costs of production. Dividing each side of (16) by $B d$, the Euler equation can be written

$$
\begin{aligned}
\mathrm{k}_{t+1} & -\left[I+\frac{I}{\beta}+\frac{A_{I} f^{2} n}{d}\right] R_{t}+\frac{1}{\beta} R_{t-1} \\
& =\frac{n}{d} w_{t}-\frac{n f A_{0}}{d}+\frac{A_{1} f_{n}}{d} \varepsilon_{t} \\
& -d^{-1}{ }_{\text {InA }} D_{1 t}-\frac{f n}{d} u_{t}
\end{aligned}
$$

It can easily be proved that there exists a $\lambda$ such that

$$
\left[1-\left(I+B^{-1}+A_{1} f^{2} n d^{-1}\right) I+B^{-I} L^{2}\right]=\left(1-(\lambda \beta)^{-1} L\right)(I-\lambda I)
$$

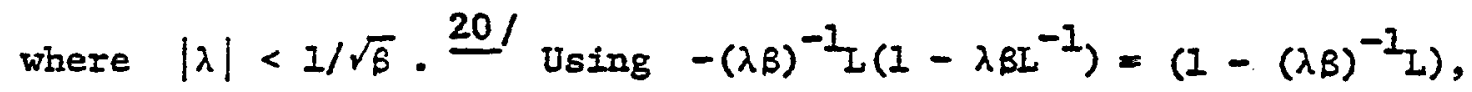
we have that the Euler equation (18) can be written as 


$$
\begin{gathered}
-(\lambda B)^{-I} L\left(I-\lambda \beta L^{-I}\right)(I-\lambda I) R_{t+1}=\frac{-n f A_{0}}{d}+\frac{n}{d} w_{t} \\
\quad+\frac{A_{1} f n}{d} \varepsilon_{t}-\frac{f D}{d} A_{2} D_{I t}-\frac{f n}{d} u_{t}
\end{gathered}
$$

A solution of the Euler equation that also satisfies the transversality condition for the social planning problem is

$$
\begin{aligned}
& (1-\lambda L) K_{t+1}=\frac{+\lambda \beta \tilde{B A} A_{0}}{d}(I-\lambda \beta)^{-1}-\frac{n \lambda \beta}{d} \frac{L^{-1}}{1-\lambda Q^{-1}} w_{t} \\
& -\frac{A_{1} \operatorname{fn} \lambda \beta}{d} \frac{L^{-1}}{1-\lambda \beta I^{-I}} \varepsilon_{t}+\frac{{\operatorname{fn} \lambda \beta I^{-1}}_{L}^{-I}}{1-\lambda \beta I^{-1}} A_{2} D_{1 t} \\
& +\frac{\operatorname{mn} \lambda A^{-1} L^{-1}}{1-\lambda \Omega^{-1}} u_{t}
\end{aligned}
$$

Recall, for example, that $\left(I-\lambda \beta L^{-1}\right)^{-I} w_{t}=j_{j=0}^{\infty}(\lambda \beta)^{j} w_{t+j}$. Then it can be recognized that equation (19) is the perfect foresight solution of the planning problem that the rational expectations competitive equilibrium implicitly solves. Thus, equation (19) expresses the aggregate capital stock $R_{t}$ as a linear function of $K_{t}$ and all future values of $w_{t}, \varepsilon_{t}, D_{I t}$, and $u_{t}$.

By using the methods of Hansen and Sargent [23, especially appendix Al, equation (19) can be converted to the "realizable" law for $\mathrm{K}$ that satisfies the Euler equations and transversality conditions, and which expresses $k_{t+1}$ as a function only of information known at time t. 2I/ This involves replacing the terms $w_{t+i}, \varepsilon_{t+i}, b_{1 t+i}$, and $u_{t+i}$ in (19) by the corresponding mathematical expectations conditioned on $\Omega_{t^{*}}$. The resulting equilibrium law of motion for $k$ can be shown to be 
$-22-$

$(1.20)$

$$
\begin{aligned}
\mathrm{K}_{t+1}=\mathrm{H}_{0} & +\mathrm{H}_{\mathrm{w}}(\mathrm{L}) \mathrm{W}_{t}+\mathrm{H}_{D}(\mathrm{~L}) \mathrm{D}_{t}+\mathrm{H}_{\varepsilon}(\mathrm{L}) \varepsilon_{t} \\
& +\mathrm{H}_{\mathrm{u}}(\mathrm{L}) \mathrm{u}_{t}+\mathrm{H}_{1} \mathrm{~K}_{t}
\end{aligned}
$$

where $\quad H_{0}=\frac{+\lambda \beta n f A_{0}}{d(I-\lambda \beta)}$

$$
\begin{aligned}
& \mathrm{H}_{1}=\lambda \\
& H_{w}(I)=\frac{-n \lambda \beta}{d} \phi_{w}\left[\frac{L^{-I}\left(I-\delta_{w}(\lambda \beta)^{-1} \delta_{w}(I)\right)}{I-\lambda \beta L^{-I}}\right] \\
& H_{\varepsilon}(I)=\frac{-A_{1} \operatorname{In} \lambda \beta}{d}\left[\frac{I^{-1}\left(I-\delta_{\varepsilon}(\lambda \beta)^{-1} \delta_{\varepsilon}(I)\right)}{1-\lambda \beta L^{-1}}\right] \\
& H_{u}(I)=+d^{-1} E I \lambda B\left[\frac{I^{-I}\left(1-\delta_{u}(\lambda \beta)^{-I} \delta_{u}(I)\right)}{I-\lambda B L^{-I}}\right]
\end{aligned}
$$

(1.2I)

Here $\phi_{w}$ is a $1 \times q$ vector with 1 in the first position, followed by $(q-1)$ zeroes, and $\phi_{D}$ is a $P_{1} \times p$ matrix with a $\left(P_{1} \times P_{1}\right)$ Identity matrix as the first $P_{1}$ columns and zeroes elsewhere. Notice that $w_{t} \equiv \phi_{w} w_{t}$ and $D_{I t} \equiv \phi_{D_{t}} D_{t^{*}}$ It is convenient at this point to recall the laws of motion assumed for $w_{t}, u_{t}, \varepsilon_{t}$ and $D_{1 t}$, namely

$$
\delta_{w}(\mathcal{I}) W_{t}=\nabla_{t}^{W}
$$

$$
\delta_{u}(L) u_{t}=v_{t}^{u}
$$

$$
\delta_{D}(I) D_{t}=V_{t}^{D}
$$

$$
\delta_{\varepsilon}(I) \varepsilon_{t}=\nabla_{t}^{E}
$$


Equation (20) expresses the equilibrium law for the industrywide capital stock $k_{t+1}$ as a linear function of $k_{t}$, and current and past values of $W, D, \varepsilon$, and $u$. Current and past values of $W$ appear in (20) because they help predict future values of the rental rate $w_{t}$, while current and past values of $D, \varepsilon$, and $u$ appear because they are used by agents to predict the future course of the market price $P$. The number of lagged values of $W, D, \varepsilon$, and $u$ in (20) are $r_{w}-1, r_{D}-1, r_{\varepsilon}-1$, and $r_{u}-1$, as expressions (21) can be used to show. $\frac{22}{\prime}$ Thus, the numbers of lagged values of these "information variables" $W, D, \varepsilon$, and $u$ in (20) are entirely inherited from the specifications of the actual laws of motion for $W, D, \varepsilon$, and $u$ in $(8),(5),(2)$ and (4).

Notice that the appearance of $w_{t}$ and $D_{I t}$ in the objective function of the representative firm (9) (or equivalently in the objective function of the fictitious social planner (17)) gives rise to the appearance in (20) of the entire blocks of variables $W_{t}$ and $D_{t}$ that help predict $w$ and $D_{1 t}$, respectively. Thus any variables that help predict $w$ and $D_{1 t}$, and wich agents have information on, belong in the equilibrium law of motion for industry wide capital. The property that the remaining variables in $W$ (or $D)$ help predict future values of $w$ (or $D_{1}$ ) is said to be the property that the remaining variables in $W$ (or D) Granger cause $w$ (or $D_{1}$ ). The notion of Granger causality thus turns out to be coincident with the criterion for whether random variables that don't themselves appear in the agent's criterion function nevertheless end up in the equilibrium law of motion or decision rule, essentially because they appear in the agents' constraints as information variables that help 
predict variables that do appear in the criterion function. It is mainly for this reason that the concept of Granger causality has played an important role in work with rational expectations models. $\underline{23 \prime}$

Equations (20) and (21) reveal explicitly how the parameters of the equilibrium law of motion for industry wide capital are themselves nonlinear functions of the underlying parameters $\left\{_{0}, A_{1}, A_{2}\right.$, $\left.E, d, \beta, \pi, \delta_{w}(L), \delta_{u}(L), \delta_{\varepsilon}(L), \delta_{D}(L)\right\}$. The nonlinearity has two sources. First, there is the fact that $\lambda$ is a nonlinear function of $B$ and $\left(A_{1} f^{2} \mathrm{nd}^{-1}\right)$ via the factorization defining $\lambda$, $\left(I-(\lambda B)^{-I} I\right)(I-\lambda I)=\left[I-\left(I+B^{-I}+A_{I} f^{2} n d^{-1}\right) I+\beta^{-1} I^{2}\right]$. Second, given $\lambda$, the formulas for $H_{W}(I), H_{U}(I), H_{E}(I)$, and $H_{D}(I)$ in (2I) are nonlinear in the parameters of $\delta_{w}(I), \delta_{v}(I), \delta_{E}(I)$ and $\delta_{D}(I)$. Nonlinear cross-equation Iestrictions of the kind illustrated by (20) and (21) are the hallmark of rational expectations models. Such cross-equation restrictions are largely absent from "pre-rational expectations" dynamic econometric models. $24 /$ The presence of these restrictions impinges on a variety of fundamental econometric and conceptual issues, including identification, the analysis of interventions, models of "error terms", and the role of "prior information". I now turn to discussing each of these issues, using (20) and (21) as an instrument. 


\section{Analysis of Interventions}

At this point, it is useful to remind ourselves of the principal reason that an economist might want to construct a dynamic econometric model of an Industry along the lines of our example. It is to be able to make quantitative predictions about the effects on the industry that various hypothetical interventions or "changes in the environment" will have. In the present context, a hypothetical "intervention" or "change in the enviromment" means a change in one of the polynomials $\delta_{W}(L), \delta_{U}(L), \delta_{D}(L)$, or $\delta_{\varepsilon}(I)$ that describe respectively, the stochastic processes for $W, u, D$, and $\varepsilon$, that impinge on the market. $25 /$. Several interesting examples of such interventions can be given, including the following:

(a) Suppose that there is a specific tax imposed on sales of the product. Such a specific tax can be modeled as a component of $\left(A_{2} D_{I t}\right)$. Since the behavior of the tax through time will be described by an element of the vector Mariov law $\delta_{D}(L) D_{t}=V_{t}^{D}$, changes in the "rule" for setting the specific tax amount to changes in one of the rows of $\delta_{D}(L)$.

(b) Suppose that there is a specific tax on the use of the factor of production. This tax can be modeled as an addition to the rental $w_{t}$. A change in the rule for setting this tax can be modeled as a change in a row of $\delta_{w}(I)$.

(c) Suppose there is a change in the structure of the process goveraing the "pre-tax" part of the rental. Again this can be modeled as a change in one row of $\delta_{w}(L)$. With a little imagination, the effects of a change in the organization of the industry $26 /$ supplying the factor might be modeled in this way. 
The model leading to (20) and (21) provides a way of predicting quantitatively the effects of such changes, once agents have caught on to them. The effect of interventions in the sense described here is to change the function (20) describing the evolution of industry capita1, in a way predicted by the formulas given in (21). Since interventions of this class change the law of motion (20), it is necessary to have analytic methods which use the "cross-equation" restrictions (2I) to predict how the H's of the K-Iaw of motion (20) will change if there is a hypothetical intervention operating on one or more of the $\delta^{\prime} s$.

In order to evaluate policy interventions in this way, it is essential that the $\mathrm{H}^{\prime} \mathrm{s}$ of (20) should not be viewed as being among the "free parameters" of the model. Instead, the model's free parameters are to be regarded as the deeper parameters $\left\{A_{0}, A_{1}, A_{2}\right.$, $\left.f, d, \delta_{w}, \delta_{u}, \delta_{\varepsilon}, \delta_{D}\right\}$. The researcher needs to know these parameters in order to be able to use the formulas (21) to predict the consequences of hypothetical changes in the functions $\delta .27$ / From the dynamic economic theory leading to (20) and (2I), it is evident that a given numerical version of (20), estimated from historical data, cannot be used to evaluate the consequences of arbitrary input sequences for $\left\{W_{t}\right\},\left\{D_{t}\right\},\left\{\varepsilon_{t}\right\}$, and $\left\{u_{t}\right\}$. That is, a fixed law of motion of the form (20) with given numerical values for the H's cannot be used to investigate the consequence of arbitrarily specified mumerical sequences for the $W, D, \varepsilon$, and $u^{\prime} s$. In effect, a particular version of $(20)$ can be expected to hold up only for $W$, $D, \varepsilon$, and $u$ sequences drawn from a restricted domain: namely, sequences obeying the probability laws (8), (4), (5), and (2). 28 ! 
However, until Iucas [34] wrote in 1973, evaluating the effects of interventions in this inappropriate way was the accepted procedure in both the meroeconometric and the microeconometric literatures. Regrettably, to this day it remains the procedure used in the overwhelming majority of analyses of policy interventions. It should be emphasized once again that from the viewpoint of the dynamic decision theory described above, the question of how agents will respond to "arbitrary sequences" of "forcing variables" $W, u, \varepsilon$, and $D$ is not well posed. In effect, unless the researcher specifies precisely the perceived laws of motion for the "forcing variables", he has not specified tie constraints subject to which decision makers are thought to be acting. 29 l

Thus, in order to be able to evaluate interventions operating on the $\delta^{\prime} s$, it is pecessary to formulate and estimate the model in terms of the parameters of preferences $\left(A_{0}, A_{1}, A_{2}\right)$, technology (f, and $d$ ), and the constraints (the $\delta^{\prime} s$ ). The argument in favor of formulating and estimating the dynamic model at the level of the deep parameters $\left\{A_{0}, A_{1}, A_{2}, d, f, \delta_{w}, \delta_{u}, \delta_{\varepsilon}, \delta_{D}\right\}$ is in much the same spirit as the usual justification for estimating "structural" parameters rather than reduced form parameters. As Marschak [40] argued, the researcher wants to estimate those objects which will permit him to aralyze an interesting class of changes in the enviroment. Dynamic economic theory has forced us to re-examine whether objects long thought to be "structural", including the parameters of decision rules such as consumption, investment, and portfolio

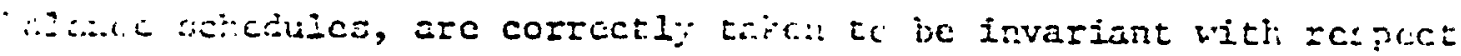
to ciarges in the environment. Once agents' behavior is modeled in terms of genuinely dynamic optimization problems, it becomes apparent that the parameters of observed decision rules should not be viewed as 
structura] (see Muth [47], Iucas and Prescott [37], Iucas [33], and Merton [42]).

\section{The Neglect of Learning}

At this point it is worthwhile to discuss a modification of the preceding kind of setup which several economists have apparently had in mind. 30 For this purpose it is sufficient to consider the problem of maximizing the social welfare criterion subject to the given laws of motion (8), (4), (5) and (2) for $W_{t}, u_{t}, D_{t}$, and $\varepsilon_{t}$. By relabeling and reinterpreting the variables, we can think of this as a choice problem faced by a single private agent. In posing this problem, it was assumed that the "agent" solving the problem knows the true values of the parameters of the objective function (17) and the true values of the polynomials in the lag operator $\delta_{\varepsilon}(L)$, $\delta_{u}(I), \delta_{D}(I)$, and $\delta_{W}(L)$. The observation has been made that this setup fails to incorporate a model of how the "agent" optimally learns about the $\delta^{\prime} s$ from observations on past realizations of the forcing variables $\varepsilon, U, D$, and $W$. Presumably, if the "agent" has only finite histories of observations on $\varepsilon, u, D$, and $W$ at his disposal, then at each point in time he is uncertain about the parameters of the polynomials $\delta$. Why not modify the preceding setup to include uncertainty about the $\delta^{\prime} s$ and a model of optimal learning about the $\delta^{\prime} s$ ? There seem to be three reasons for why such extensions have not as yet successfully been incorporated into rational expectations models.

The first is as follows. A general model of optimal learning about the $\delta$ 's is readily available in the "Talman filter". The Kalman filter can be used to model how a rational agent would use observations on ( $\varepsilon_{t}$, $u_{t}, D_{t}, W_{t}$ ) to revise his prior beliefs about the $\delta^{t} s .31 /$ However, with the $\delta^{\prime} s$ uncertain, it is no longer possible to give closed form formulas 
for the optimal decision rule in terms of what are now the posterior probability distributions over the $\delta^{\prime} s$. The reason that no one has yet obtained or is likely ever to obtain such closed formulas is as follows. In derfving the closed form of the restrictions (21) for the case in which the $\delta^{\prime} s$ are assumed known with certainty, the Wiener-KoImogorov prediction formula

$$
E_{t} W_{t+i}=\left[\frac{\delta w(L)^{-1}}{L^{I}}\right]+\delta(L) W_{t}
$$

was used extensively. Here $\left[\sum_{j=-\infty}^{\infty} a_{j} L^{j}\right]_{+}=\sum_{j=0}^{\infty} a_{j} L^{j}$, so that []$_{+}$ means "ignore negative powers of $I$ ". The Hiener-Kolmogorov formula is equivalent with the "chain rule" of forecasting (see Shiller [55] or Sargent [54] for expositions). These equivalent forecasting rules are known to be correct for the case in which the $\delta$ 's are known with certainty. However, as Chow [6] has pointed out, where there is a nontrivial posterior density over the $\delta^{\prime} s$, there is in general no known closed form formula such as the above one for the i-step ahead forecast. For example, it is not true that where $\delta$ is uncertain, the cerzect exfression for $E_{t} \eta_{t+i}$ is given by replacino the $\delta_{k_{0} j}$ 's witi. ticir posterior means in the above formula. The fact that there is no closed form prediction formula for sufficiently general cases implies that it is impossible to derive closed form versions of decision rules (and hence equilibria) that correspond to (21). As we shall see, for the kind of empirical work we are advocating, it is important to have a closed form for the mapping from the parameters of the objective functions (17) and the dynawic constraints to the decision rule (20). From this viewpoint, the suggestion that one ought to build a learning mechanism into rational 
expectations models is not useful in suggesting practical econometric alternatives to the procedures recommended here. $\frac{32 /}{}$

Another drawback with incorporating learning is that, even if one could derive the decision rules in the face of uncertain $\delta^{\prime} s$, the issue would arise of how to determine the prior used to initiate the learning model for the $\delta^{\prime} s$. Would it be imposed a priori or estimated? If the initial prior were to be estimated, this would substantially complicate the estimation problem and add to the number of parameters. Finally, in many settings the Bayesian learning model implies that the posterior distributions collapse about the true $\delta^{\prime} s$ as time passes without limit. In such settings, even if the researcher erroneously assumes that the $\delta^{\prime} s$ are known with certainty when in reality agents are learning about them in an optimal way, the researcher continues to obtain consistent estimators of the underlying parameters $\left\{A_{0}, A_{1}, A_{2}\right.$, $f, d, \delta_{W}, \delta_{D}, \delta_{E}, \delta_{u}$ ] using the methods described here and in Hansen [20] and Hansen and Sargent [23]. It does seem likely that by erroneousiy ignoring the phenomenon of learning about the $\delta^{\prime} s$, the researcher is incorrectly calculating the asymptotic covariance matrix of his estimators. However, at present nothing is known about the nature of this error. Further, since we simply don't know how to compute optimum decision rules under the assumption that agents know the $\delta^{\prime} s$ with uncertainty, no consistent estimators of the underlying parameters have been proposed that incorporate agents' learning about the $\delta^{\prime} s$ in the optimal way, to say nothing of expressions for the associated asymptotic covariance matrices. From the preceding considerations, I draw the conclusion that incorporating optimal Bayesian learning about the $\delta^{\prime} s$ on the part of agents is not a research avenue that soon promises appreciable dividends for the economist interested in applying dynamic competitive models of the sort described here. 
A Model of the "Error Term"

We now derive a "dymamic supply curve" for the industry by using the industry-wide production function $Y_{t}=f R_{t}+\varepsilon_{t}$ to eliminate $K$ from (20) in favor of $Y$. Multiplying both sides of (20) by $f$ then adding $\varepsilon_{t+1}$ to both sides gives

$$
\begin{aligned}
Y_{t+1} & =H_{0} f+f H_{w}(L) w_{t}+f H_{D}(I) D_{t} \\
& +E H_{\varepsilon}(L) \varepsilon_{t}+f H_{u}(I) u_{t} \\
& +H_{1} Y_{t}+\varepsilon_{t+1}-H_{I} \varepsilon_{t}
\end{aligned}
$$

Eliminating $u_{t}$ by using $u_{t}=P_{t}-A_{0}+A_{I} Y_{t}-A_{2} D_{I t}$ gives

$$
\begin{aligned}
\Psi_{t+1} & =\left[H_{0} f-f H_{u}(I) A_{0}\right]+f H_{u}(I) P_{t}+f E_{w}(I) W_{t} \\
& +\left[f H_{D}(L)-I H_{u}(L) A_{2} \phi_{D}\right] D_{t} \\
& +\left[H_{1}+E H_{u}(I) A_{1}\right] Y_{t} \\
& +\left[I+f H_{\varepsilon}(I) L-H_{I} L\right] \varepsilon_{t+I}
\end{aligned}
$$

This can be written as

$$
\begin{aligned}
Y_{t+I} & =S_{0}+S_{P}(L) P_{t}+S_{W}(I) W_{t} \\
& +S_{D}(L) D_{t}+S_{Y}(I) Y_{t}+S_{\varepsilon}(I) \varepsilon_{t+1}
\end{aligned}
$$

where

$$
S_{0}=H_{0} f-E H_{u}(I) A_{0}
$$

$$
\begin{aligned}
& S_{p}(I)=f H_{u}(L) \\
& S_{w}(I)=f H_{w}(I)
\end{aligned}
$$




$$
\begin{aligned}
& S_{D}(I)=\left[f H_{D}(I)-\mathrm{EH}_{U}(I) A_{2} \Phi_{D}\right] \\
& S_{Y}(I)=\left[\mathrm{H}_{I}+E H_{U}(I) A_{I}\right] \\
& S_{E}(I)=\left[I+f H_{\varepsilon}(L) I-H_{I} I\right]
\end{aligned}
$$

Recall that the demand curve is

$$
P_{t}=A_{0}-A_{1} Y_{t}+A_{2} D_{1 t}+u_{t}
$$

Using $\delta_{\varepsilon}(I) \varepsilon_{t}=\nabla_{t}^{\varepsilon}$ and $\delta_{u}(I) u_{t}=v_{t}^{u}$, we can write the supply and demand curves as

$$
\begin{aligned}
Y_{t+1} & =S_{0}+S_{p}(I) P_{t}+S_{w}(L) W_{t}+S_{D}(I) D_{t} \\
& +S_{Y}(I) \dot{Y}_{t}+S_{\varepsilon}(I) \delta_{\varepsilon}(L){ }^{-I} V_{t+1}^{\varepsilon}
\end{aligned}
$$

$$
P_{t}=A_{0}-A_{1} Y_{t}+A_{2} D_{1 t}+\delta_{u}(I)^{-I} v_{t}^{U}
$$

To discuss identification and estimation of the model, we need a theory about what is unimown to the econometrician. In constructing the model, we have taken the view that all of the variables on the right hand side of the supply and demand curves (23) and (3) (or equivalently (25) and (26)) are known to the representative firm. Thus, from the viewpoint of private agents, (25) and (26) describe exact linear functions of the right side variables in which there are no "random errors". 33/ The only tractable ways that have so far been discovered of introducing "random errors" into (25) and (26) have been to assume that the econometrician has less information than do the private agents. The. smaller information set of the econometrician leads to what from his point of view are random terms 
in relationships to be derived from (23) and (3) or (25) and (26). The idea is to restrict the econometrician's information set relative to that of private agents in a way both that is plausible and that leads to a tractable statistical model of the error term. I shall describe two models of the error term that can be constructed in this way.

One model results from assuming that the econometrician has time series on $\left\{P_{t}, W_{t}, D_{t}, I_{t}\right\}$ but never observes the random processes $\varepsilon_{t}$ and $u_{t}$. On this interpretation, $\varepsilon_{t}$ and $u_{t}$ become random terms in (23) and (3) from the econometrician's viewpoint. 34 In constructing the model, we have already.imposed that $v_{t+1}^{\varepsilon}$ is orthogonal to all of the variables on the right side of (25), and will assume that $\nabla_{t}^{u}$ is orthogonal to $Y_{t}$. We can also impose that $\nabla_{t}^{u}$ is orthogonal to $D_{1 t}$, if we wish, $\frac{35 /}{}$ although we might get by with a weaker assumption.

The second model of the error term results from assuming that the econometrician sees less of $D_{t}$ and $W_{t}$ than do private agents. It is convenient to postpone a detailed discussion of this second model of the error, and instead first to discuss identification and estimation under the first model of the error term. 
Identification and Estimation

With this model of the error terms, we can proceed to discuss identification and estimation. First, notice that every variable that appears on the right side of the demand schedule (26) also appears on the right side of the supply schedule (25). The dynamic economic theory leading to (25) makes the reason for this clear, since any variables that help predict future prices $P$ will appear in the supply schedule of the representative firm. This immediately implies that any variables that help predict the demand shifters

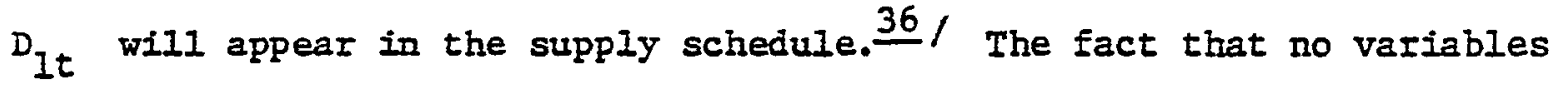
on the right side of the demand curve (26) are excluded from the supply schedule (25) means that if the supply schedule is to be identified, the source of identification must be found in restrictions of a kind different from the usual exclusion restrictions treated extensively in econometrics textbooks. 37 According to the standard "order condition" for identification, equation $(25)$ is hopelessly underidentified. 38 . So if the parameters of the model are to be identified, sources of prior information not of the exclusion variety must be available. The main source of these restrictions in the present model is the extensive body of cross equation restrictions embodied in equations (21) and (24). Equations (21) and (24) give the parameters of the supply schedule (25) as nonlinear functions of the parameters $\left\{A_{0}, A_{1}, A_{2}\right.$, $f, d, \beta, D, \delta_{w}(I), \delta_{D}(I), \delta_{U}(I)$, and $\left.\delta_{E}(I)\right\}$. In general, provided that the parameters $I_{D}$ and $I_{w}$, which determine the order of the autoregressive processes for $D$ and $W$ and the parameters $p$ and $q$, the number of elements in the vectors $D$ and $W$, respectively, are large enough, these cross equation restrictions identify or over- 
identify the parameters of the model. The strength of overidentification generally increases with increases in the orders $r_{D}$ and $r_{w}$ and the dimensions $p$ and $q .39$ !

At this point it is useful to collect together the equations comprising the model as

$$
\begin{aligned}
Y_{t+I} & =S_{0}+S_{p}(L) P_{t}+S_{W}(L) W_{t}+S_{D}(I) D_{t} \\
& +S_{Y}(L) Y_{t}+S_{\varepsilon}(L) \delta_{\varepsilon}(I)-1 V_{t+1}^{\varepsilon}
\end{aligned}
$$

(1.26) $\quad P_{t}=A_{0}-A_{1} Y_{t}+A_{2} D_{1 t}+\delta_{u}(L)^{-1} V_{t}^{11}$

$$
\oint_{w}(L) W_{t}=v_{t}^{w}
$$

$$
\delta_{D}(L) D_{t}=V_{t}^{D}
$$

where

(27)

$$
\begin{aligned}
& s_{0}=+f^{2} \lambda_{a B A_{0} d^{-I}}-f H_{u}(I) A_{0} \\
& S_{p}(I)=+f^{2} n \lambda B d^{-1}\left[\frac{L^{-1}\left(I-\delta_{U}(\lambda \beta)^{-1} \delta_{U}(I)\right)}{1-\lambda \beta L^{-1}}\right] \\
& S_{w}(I)=\frac{-n \lambda \beta f}{d} \phi_{w}\left[\frac{L^{-1}\left(I-\delta_{w}(\lambda \beta)^{-1} \delta_{w}(L)\right)}{I-\lambda L^{-1}}\right] \\
& S_{D}(L)=+E^{2} n \lambda \beta d^{-1} A_{2} \phi_{D}\left[\frac{L^{-1}\left(I-\delta_{D}(\lambda \beta)^{-1} \delta_{D}(L)\right)}{1-\lambda \beta L}\right] \\
& -f^{2} d^{-1} n \lambda \beta\left[\frac{L^{-1}\left(I-\delta_{u}(\lambda \beta)^{-1} \delta_{u}(L)\right)}{1-\lambda \beta L^{-1}}\right] A_{2} \phi_{D}
\end{aligned}
$$




$$
\begin{aligned}
& S_{Y}(I)=\quad+f^{2} d^{-1} n \lambda \beta A_{I}\left[\frac{L^{-1}\left(I-\delta_{u}(\lambda \beta)^{-1} \delta_{u}(L)\right)}{1-\lambda L^{-1}}\right]+\lambda \\
& S_{\varepsilon}(I)=1-\frac{A_{1} f^{2} I \lambda B}{d}\left[\frac{I-\delta_{\varepsilon}(\lambda B)^{-I} \delta_{\varepsilon}(I)}{1-\lambda \beta L^{-I}}\right]-\lambda I \cdot \\
& \left(1-(\lambda B)^{-I} L\right)(1-\lambda I)=\left[I-\left(1+\beta^{-1}+A_{1} f^{2} n d^{-1}\right) I+\beta^{-1} L^{2}\right] .
\end{aligned}
$$

Equations (25), (26), (8), and (5) form a statistical model for the joint process $\left(P_{t}, Y_{t}, W_{t}, D_{t}\right)$. The model is linear in the variables, but is characterized by the extensive set of cross-equation restrictions described by (27). With the model of the error terms currently under discussion, the statistical model of the $\left(P_{t}, Y_{t}\right.$, $\left.W_{t}, D_{t}\right)$ process has been spelled out sufficiently completely that we could write down the likelihood function for a sample ( $P_{t}$, $Y_{t}$, $\left.W_{t}, D_{t}\right), t=1, \ldots, T$ assuming a normal probability density for $\left(\nabla_{t}^{W}, \nabla_{t}^{U}, \nabla_{t}^{D}, \nabla_{t}^{\varepsilon}\right) .40 /$ Maximum Iikelihood estimates of the free parameters of the model $\left\{A_{0}, A_{1}, A_{2}, f, d, \delta_{D}(I), \delta_{W}(I), \delta_{u}(I)\right.$, $\left.\delta_{\varepsilon}(I)\right\}$ could then be obtained. Computational details of such procedures are described by Sargent [51, 52] and Hansen and Sargent [23]. From the point of view of computing the estimates, it is a great practical advantage that (27) gives a set of closed-form formulas for the cross-equation restrictions imposed by the dynamic economic theory. 
Application of Bayesian Methods

The fact that for the present model of the error terms it is possible to write down a normal likelihood function means that in principle Bayesian methods are applicable. Letting $\theta$ be the list of parameters of the model, and $z$ be the data, we have

$$
f_{\text {post }}\{\theta \mid z\}=\frac{l\{z \mid \theta\} f_{\text {prior }}\{\theta\}}{f(z)}
$$

or

$$
\text { (1.28) } f_{\text {post }}\{\theta \mid z\}=\ell(z \mid \theta) f(\theta) / \int \ell(z \mid \theta) f_{\text {prior }}(\theta) \mathrm{d} \theta
$$

where $f_{\text {post }}\{\theta \mid z\}$ denotes the posterior probability density, $f(z)$ the probability density of $Z$, $f_{\text {prior }}\{\theta\}$ the prior density on $\theta$, and $l\{z \mid \theta\}$ the Iikelihood function. Measures of the location and dispersion of the posterior distribution of $\theta$ can be calculated, for example, by integrating $\theta^{k}$. post $\{\theta \mid z\}$ over $\theta$ for appropriate values of $k$. In the Bayesian view, the role of data analysis is to trace out in as revealing a way as possible the mapping defined by (28) from the prior to the posterior distribution. For such an analysis to be practical, it substantially eases matters if the mapping (28) can be characterized analytically, so that for example, posterlor moments such as $\int \theta f_{\text {post }}(\theta \mid z) d \theta$ can be calculated without the need to resort to numerical integration. Leamer [32] and zeliner [61] describe forms of prior densities $f_{\text {prior }}(\theta)$ that have the property that the mapping $(28)$ is one that can be written as an analytic closed form when $l(z \mid \theta)$ is the normal likelihood function.

In the context of dynamic economic models of the class represented by (25), (26), (8) and (5), the question of whether the mapping (28) can be characterized analytically hinges on which parameters one regards 
as being in the list $\theta$ about which the researcher has formulated prior information. One possibility is that $\theta$ consists of the $S^{\prime} s$ of (25), the $A^{\prime} s$ of $(26)$, and $\delta_{w}, \delta_{u}$ and $\delta_{D}$ of $(26),(8)$ and (5). With this interpretation of $\theta$, then since (25), (26), (8), and (5) are linear in the $s^{\prime} s, A^{\prime} s, \delta_{w}$ and $\delta$, it is possible to get analytic characterizations of the mapping from $f_{\text {prior }}(\theta)$ to $f_{\text {post }}(\theta \mid z)$. For example, Shiller [55] and Leamer [31] have shown how priors of various forms on the S's in (25) can tractably be mapped into posteriors, in contexts where (25) is appropriately viewed as a regression equation. In effect, Leamer [31] and Shiller [55] provided formal Bayesian methods for imposing Iestrictions on lag distributions of a general kind, eramples of which had long been imposed by applied econometricians. These restrictions usually corresponded to restrictions directly on our $S_{j}$ 's. Pre-dating the work of Shiller and Leamer were the restrictions on distributed lags proposed by Koyck [ ], Friedman [ ] and Cagan [ ], Jorgenson [ ], and A]mon [ ]. There was also the frequently used identifying restriction that various distributed lag weights sum to unity. $41 / 4 I I$ of these approaches view the S's themselves as among the "free parameters" of the model about which the researcher can reasonably be imagined to have formed views sumarized by a prior distribution.

Unfortunately, the tractability of the Leamer-Shiller approach is purchased at the cost of ignoring the essential aspects of the dynamic economic theory leading to (25). According to that theory, the $S^{\prime} s$ are not free parameters, but are complicated functions of the parameters $\left\{A_{0}, A_{1}, A_{2}, E, d, B, D, \delta_{w}(I), \delta_{D}(I), \delta_{u}(L), \delta_{\varepsilon}(I)\right\}$. It is this list of parameters about which it seëms most appropriate to expect an economist to have prior beliefs. The parameters $\left\{A_{0}, A_{1}, A_{2}\right.$, f,d\} are the parameters describing preferences and the technology, 
about which the economic theorist may have some prior beliefs. The economists' "prior beliefs" about the parameters $\left\{\delta_{w}, \delta_{D}, \delta_{u}, \delta_{\varepsilon}\right\}$ are presumably on a different theoretical footing from his beliefs about $\left\{A_{0}, A_{1}, A_{2}, f, d\right\}$, since the former list simply characterizes the serial correlation properties of the "shift variables" about which economic theory itself suggests little, although casual general observations may suggest a presumption in favor of high serial correlation, at least in some types of variables. In any event, it is the "deep" parameters $\left\{A_{0}, A_{I}, A_{2}, f, d, \beta, n, \delta_{w}, \delta_{D}, \delta_{u}, \delta_{\varepsilon}\right\}$ that must be estimated, if one is to build a model that potentially overcomes Iucas's critique of econometric policy evaluation procedures. 421

wher this list of "deep" parameters contains the objects of intertst: Bayesian analysis using (28) becomes much less tractable. This is because the likelihood function $2(z \mid \theta)$ becomes a very complicated function of the free parameters in $\theta$, by virtue of the complicated nature of the cross-equation restrictions illustrated in (27). Although Bayesian analysis is still possible, the researcher will be forced to use numerical methods to characterize the mapping from the prior to the posterior given in (28). For example, for a given prior, numerical integration will have to be used to calculate the moments of the posterior distribution. Ify own judgement is that given current computer technology, formal Bayesian estimation procedures seem probibitively expensive for most members of the class of dynamic models considered here. This is obviously not an objection to Bayesian methods in principle. However, I believe that the high cost attached to applying Bayesian methods correctly helps to explain why they have not yet been applied extensively to estimating rational expectations models. 


\section{A Second Model of the "Error Term"}

More serious limitations on the domain of Bayesian techniques emerge if the researcher embraces a second model of the error term, which we now discuss. In the second model of the error term, it is assumed that the econometrician possesses only observations on subsets $\tilde{W}_{t} \subset W_{t}$ and $\tilde{D}_{t} \subset D_{t}$ of the information variables that private agents use to forecast future $w_{t}^{\prime}$ s and $D_{1 t}$ 's.43/ It is assumed that these subsets of information variables follow autoregressive processes

$$
\begin{aligned}
& \tilde{\delta}_{D}(L) \tilde{D}_{t}=\tilde{V}_{t}^{D} \\
& \tilde{\delta}_{W}(L) \tilde{W}_{t}=\tilde{v}_{\tau}
\end{aligned}
$$

where $\tilde{\delta}_{D}(\mathrm{I})$ and $\tilde{\delta}_{W}(I)$ are polynomials in the lag operator of of order $\tilde{I}_{D}$ and $\tilde{I}_{W}$, respectively. Then it turns that the equilibrium law of motion for capital (20) can be written in a form identical to $(20)$, except that $W, D, \delta_{D}, \delta_{W}, H_{D}$, and $H_{W}$ are to be replaced by the corresponding objects with tildes above them, and that there appears a random disturbance $\eta_{t}$ on the right side of (20). The cross-equation Iestrictions (21) continue to characterize the objects

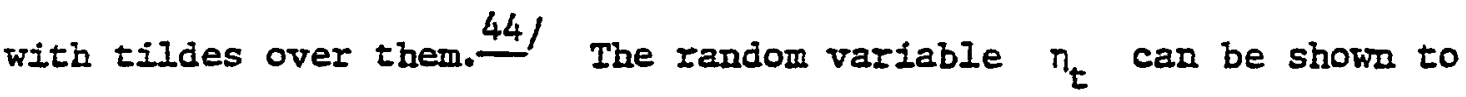
be orthogonal to all of the current and lagged values of $\tilde{W}$ and $\tilde{D} \cdot \frac{45 /}{}$ However, it turns out that $\eta_{t}$ is in general serially correlated, with serial correlation properties that depend on the joint covariance properties of those variables in $D_{t}$ and $W_{t}$ that the econometrician does not have observations on. In the context of this setup, it is not even possible to write down the likelihood function without specifying details of the moments of information variables in $D$ 
and $W$ that are unobservable to the econometrician. It would seem attractive to adopt an estimation procedure that avoids the implicit theorizing about the stochastic properties of the unobserved $D^{\prime} s$ and $W^{\prime} s$ that an estimator using the Iikelihood function requires. One such estimation strategy that exploits the orthogonality of $n$ to $\tilde{D}$ and $\tilde{W}$, without requiring all of the added details required to write down a likelihood function, has been developed by Lars Hansen [20]. The "generalized method of moments" estimators of Hansen have the advantage of delivering estimators of the free parameters whose desirable statistical properties don't depend on any arbitrary assumptions about the serial correlation properties of the $n_{t}{ }^{\prime} s_{0}$ / These generalized method of moments estimators were invented precisely to handle situations in which the researcher is substantially more confident of the orthogonality conditions delivered by his theorizing than he is about the serial correlation properties of the error. These methods construct statistically consistent estimators, while avoiding the need to form the Iikelihood function. However, in acknowiedging that he does not have enougin information about the distrubances to construct the likelihood function, the researcher looses the ability to employ Bayesian methods, since knowledge of the likelihood function is essential for using Bayes' law as in (28). 


\section{A Model of the Corn-Hog Cycle}

This section illustrates in a general way how a model of an important phenomenon, the "corn-hog cycle", might be constructed in a fashion consistent with the principles recomended above. Technically, the corn-hog cycle is defined as the occurrence of distinctive patterns of serial correlation and cross-serial correlation between various measures of output flows, stocks, and prices of corn and hogs. A model of the behavior of such series might be useful either for the positive analysis of various tax and subsidy schemes designed to ameliorate the "cycle", or for the welfare of analysis of alternative policies. The simple model I shall describe is mainly directed at the first use, but might also be used for the second purpose.

The corn-hog example also illustrates an important methodological point. The Iucas-Prescott example described in section 1 has the feature that aIl the state variables $W_{t}$ that heip predict future values of the input price $w_{t}$ appear in the equilibrium laws of motion for capital and output. This suggests that since the "hog industry" purchases corn, the state variables which characterize the corn market will appear in the equilibrium laws of motion for the state variables that characterize the hog market. Similar reasoning suggests that the corn market will inherit all of the state variables characterizing the hog market. To take this into account properly will require, for example, that for the hog industry the stochastic process for one of its inputs, which corresponds to $\delta_{W}(I)$ in $(1.8)$, can no longer be regarded as deterwined from outside the model. Instead, the markets become intimately interrelated, and their equilibria must be defined jointiy. 
The purpose of this section is to illustrate the nontrivial modifications of the setup of section 1 that would be required for various "realistic" applications. The model of the corn-hog cycle described here still does not realistically describe the dynamics of the actual corn and hog industries. More realism could be attained at the cost of proliferating state variables, but at no real cost in terms of analytical difficulty. However, the example described here will convey the sense in which the internal logic of models of this class tends to push the analyst toward a general equilibrium approach.

We now define the following variables:

$c_{t}=$ output of the representative corn farmer

m. number of corn farmers

$C_{t} \quad=$ total output of corn $\left(C_{t}=m c_{t}\right)$

$P_{\text {ct }} \quad x$ price of corn

$D_{1 t}^{c}=a\left(p_{1}^{c} \times 1\right)$ vector of random variables appearing in the demand schedule for final consumption of corn

$D_{2 t}^{c}=a\left(p^{c}-p_{I}^{c}\right) \times I$ vector of random variables that help predict the future values of the collection of random variables $p_{I t}^{c}, p^{c} \geq p_{I}^{c}$.

$D_{t}^{c}=\left[\begin{array}{c}D^{c} \\ D_{2 t}^{c}\end{array}\right]$

$k_{c t}=$ capital stock of representative corn farmer

$K_{c t}=m_{c t}=$ total capital stock in the corn industry. 
$w_{t}^{c}=$ real rental rate on capital in the corn industry.
$w_{t}^{c}=a\left(q^{c} \times 1\right)$ vector whose first element is $w_{t}^{c}$; the remaining variables of $W_{t}^{c}$ are variables that help predict future values of $w^{c}$.

$h_{t}=$ flow output of hogs of the representative hog farmer.

II $\quad=$ number of hog farmers.

$\mathrm{H}_{t}=$ total output of hogs $\left(\mathrm{H}_{t}=\mathrm{nh}_{t}\right)$.

$c_{\text {ht }}=$ consumption of corn by hogs at the representative hog farm.

$k_{\text {ht }}=$ number of hogs at the representative hog farm.

$K_{h t}=$ total number of hogs at hog farms $k_{h t}=n k_{h t}$.

$w_{t}^{h_{k t}}=$ miscellaneous expenses needed to maintain $k_{h t}$ hogs at the representative hog farm.

$w_{t}^{h}=a\left(q^{h} \times 1\right)$ vector whose first element is $w_{t}^{h}$; the remaining variables of $w_{t}^{h}$ are variables that help predict future values of $w$.

$P_{h t}=$ flow price of hogs

$D_{l t}^{h}=a\left(p_{1}^{h} \times 1\right)$ vector of random variables appearing in the demand schedule for final consumption of hogs.

$D_{2 t}^{h}=a\left(p^{h}-p_{1}^{h}\right)$ vector of random variables that help predict the Euture values of the collection of variatles $D_{1}^{h}, p^{h} \geq p_{1}^{h}$.

$D_{t}^{h}=\left\{\begin{array}{c}D_{1 t}^{h} \\ D_{2 t}^{h}\end{array}\right\}$

$\varepsilon_{c t}=a$ random shock in the production function for corn.

$\varepsilon_{\text {ht }}=$ a random shock in the production technology for hog farming.

$u_{c t}=$ a random shock to the demand for final consumption of corn.

$u_{\text {ht }}$, a random shock to the flow demand for consumption of hogs. 
We further define the following polynowials in the lag operator

L:

$$
\begin{aligned}
& \delta_{u}^{c}(L)=1-\sum_{j=1}^{r_{u}^{c}} \delta_{u j}^{c} I^{j}, \quad \text { where } \delta_{u j}^{c} \text { is a scalar } \\
& \delta_{u}^{h}(L)=1-\sum_{j=1}^{r_{u}^{h}} \delta_{u j}^{h} I^{j}, \quad \text { where } \delta_{u j}^{h} \text { is a scalar }
\end{aligned}
$$

$\delta_{D}^{c}(I)=I_{p} c-\sum_{j=1}^{I_{D}^{c}} \delta_{D j}^{c} I^{j}, \quad$ where $\delta_{D j}^{c}$ is a $p^{c} \times p^{c}$ matrix, and $\begin{array}{rr}\delta_{D}^{h}(I)=I_{p h}-\sum_{j=I}^{I_{D}^{h}} \delta_{D j}^{h} I^{j}, & \text { where } \delta_{D j}^{h} \text { is a } p^{h} \times I^{h} \text { is the }\left(p^{h} \times p^{h}\right) \\ \delta_{\varepsilon}^{c}(L)=1-\sum_{j=1}^{c} \delta_{\varepsilon j}^{c} I^{j}, & \text { where } \delta_{\varepsilon j}^{c} \text { is a scalar }\end{array}$ $\delta_{\varepsilon}^{h}(I)=I-\sum_{j=1}^{r_{\varepsilon}^{h}} \delta_{\varepsilon j}^{h} I^{j}$, where $\delta_{\varepsilon j}^{h} \quad$ is a scalar. $\delta_{w}^{c}(I)=I_{q} c-\sum_{j=1}^{r_{w}^{c}} \delta_{w j}^{c} I^{j}$, where $\delta_{w j}^{c}$ is a $\left(q_{c} \times q_{c}\right)$ matrix. $\delta_{w}^{h}(L)=I_{q h}-\sum_{j=I}^{r_{w j}^{h}} \delta_{w j}^{h} I^{j}$, where $\delta_{w j}^{h}$ is a $\left(q_{h} \times q_{h}\right)$ matrix.

I shall assume that for each polynomial $\delta$ the zeroes of det $(z)$ exceed $\sqrt{\beta}$ in modulus, where $\beta$ is the discount factor introduced below.

There are in identical corn farmers, each of whom maximizes

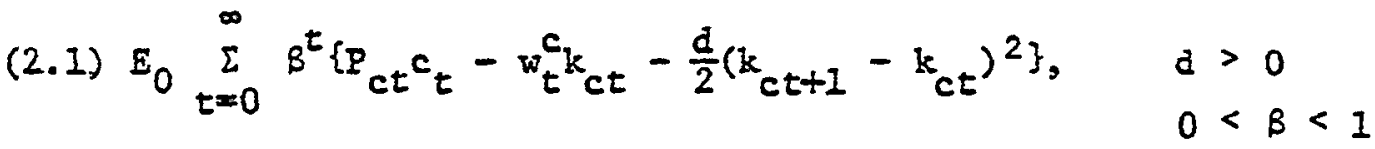

where $P_{c t}$ is the price of corn, $c_{t}$ is output of corn, $k_{c t}$ is 
the capital stock of the corn producer, and $w_{t}^{c}$ is the rental rate on capital in the corn-growing industry. Output of corn obeys

$$
c_{t}=f k_{c t}+m^{-1} \varepsilon_{c t}, \quad E>0
$$

where $\varepsilon_{c t}$ is a random process. The productivity shock $\varepsilon_{c t}$ is assumed to follow the $r_{\varepsilon}^{c}$ th order Markov process

$$
\text { (2.3) } \quad \delta_{E}^{c}(L) \varepsilon_{c t}=v_{\varepsilon t}^{c}
$$

where $\nabla_{\varepsilon t}^{c}$ is a fundamental white noise for $\varepsilon_{c t^{*}}$. The corn producer faces the stochastic processes for $P_{c t}$ and $w_{t}^{c}$ as a price taker. The rental $w_{t}$ is assumed to be the first element of $a q^{c} \times I$ vector random process that obeys the $r_{W}^{c}$ th order vector Markov process

$$
\delta_{w}^{c}(L) W_{t}^{c}=V_{w t}^{c}
$$

where $\nabla_{w t}^{c}$ is a $(q \times I)$ vector white noise that is fundamental for $w_{t}^{c}$. The assumptions about the stochastic process for $P_{c t}$ and the representative firn's perceptions of it will be filled in later. The hog industry consists of $n$ identical producers each of whom maximizes

$$
E_{0} \sum_{t=0}^{\infty} \beta^{t}\left\{P_{h t} h_{t}-w_{t}^{h_{k}} h t-e / 2\left(k_{h t+1}-k_{h t}\right)^{2}-P_{c t} c_{h t}\right\}, e>0,
$$
where $P_{h t}$ is the price of hogs, $c_{h t}$ is the consumption of corn by $k_{h t}$ hogs, $k_{h t}$ is the number of hogs, $h_{t}$ is sales of hogs, and $w_{t} k_{h t}$ is miscellaneous expenses required to maintain $k_{h t}$ hogs. The technology is assumed to be 


$$
c_{h t}=\gamma k_{h t}, \quad \gamma>0
$$

$$
h_{t}=(1+\phi) k_{h t}-k_{h t+1}+n^{-1} \varepsilon_{h t}, \quad \phi>0
$$

where $\phi$ is determined by the reproduction rate of pigs, which is assumed exogenous here, but would be a decision variable in a more realistic analysis. In (5), the term $e / 2\left(k_{h t+1}-k_{h t}\right)^{2}$ represents costs of adjusting the number of pigs rapidiy. The productivity shock $\varepsilon_{\text {ht }}$ follows the $r_{\varepsilon}^{h}$ th order process

$$
\text { (2.7) } \quad \delta_{\varepsilon}^{h}(I) \varepsilon_{h t}=\nabla_{\varepsilon t}^{h}
$$

where $v_{\varepsilon t}^{h}$ is a fundamental white noise for $\varepsilon_{h t}$. The price $w_{t}^{h}$ is the first element of a $\left(q^{h} \times I\right)$ vector $w_{t}^{h}$ that follows the $z_{w}^{h}$ th order vector Markov process

$$
\delta_{w}^{h}(L) w_{t}^{h}=v_{w t}^{h}
$$

where $v_{w t}^{h}$ is a fundamental white noise for $w_{t}^{h}$.

The flow demand for hogs is given by

$$
P_{h t}=A_{0}-A_{1} B_{t}+A_{2} D_{1 t}^{h}+u_{h t} ; \quad A_{0}>0, A_{1}>0
$$

where $A_{0}, A_{1}$ are scalars, $A_{2}$ is a $\left(1 \times p_{1}^{h}\right)$ vector, $E_{t}=n h_{t}$, and where $u_{h t}$ is a stochastic shock to demand that obeys the $r_{u}^{h}$ th order Markov process

$$
\delta_{u}^{h}(I) u_{h t}=v_{u t}^{h}
$$

where $\frac{\nabla_{u t}^{h}}{u t}$ is fundamental for $u_{h t}$. The vector of demand shifters $b_{1 t}^{h}$ is $\left(p_{1}^{h} \times 1\right)$ and consists of the first $p_{1}^{h}$ elements of the 
$\left(p^{h} \times I\right)$ vector $D_{t}^{h}$. It. is assumed that $D_{t}^{h}$ evolves according to the $r_{D}^{h}$ th order vector Markov process

(2.11) $\quad \delta_{D}^{h}(I) D_{t}^{h}=V_{D t}^{h}$.

where $v_{D t}^{h}$ is a $\left(p^{h} \times I\right)$ vector white noise that is fundamental for $D_{t}^{h}$

The demand for corn is the sum of the demand derived from hog production, $c_{h t}=n c_{h t}$, and the demand for final consumption, $c_{c t}$. The demand for final consumption obeys

$$
C_{c t}=B_{0}-B_{1} P_{c t}+B_{2} D_{1 t}^{C}+u_{c t}, \quad B_{0}, B_{1}>0
$$

where $B_{0}$ and $B_{1}$ are scalars, where $B_{2}$ is a $\left(1 \times p_{1}^{c}\right)$ vector, where $u_{c t}$ is a demand shock that obeys the $r_{u}^{c}$ th order Markov process

$$
\delta_{u}^{c}(I) u_{c t}=v_{u t}^{c}
$$

where $v_{u t}^{c}$ is a fundamental white noise for uct $_{c}$. The $\left(p_{I}^{c} \times I\right)$ vector of corn-dewand shifters $D_{1 t}^{c}$ consists of the first $p_{1}^{c}$ elements of a $\left(p^{c} \times 1\right)$ vector $D_{t}^{c}$ that follows the $I_{D}^{c}$ th order Markov process (2.14) $\quad \delta_{D}^{c}(I) D_{t}^{c}=V_{D t}^{c}$ where $v_{c t}^{D}$ is a $\left(p^{c} \times 1\right)$ vector white noise that is fundamental for $D_{t}^{c}$. The hog-derived demand for corn, from (6), is

$$
c_{h t}=\gamma_{h t}
$$

where $K_{h t}=n k_{h t}$ and $k_{c t}=m k_{c t}$. The equilibrium condition in the market for corn is

$$
c_{c t}+c_{h t}=i K_{c t}+\varepsilon_{c t}
$$




$$
B_{0}-B_{1} P_{c t}+B_{2} D_{1 t}^{C}+u_{c t}+\gamma R_{h t}=f R_{c t}+\varepsilon_{c t}
$$

which implies that

$$
\text { (2.15) } \quad P_{c t}=B_{I}^{-1}\left[\gamma R_{h t}+u_{c t}+B_{0}+B_{2} D_{I t}^{c}-f R_{c t}-\varepsilon_{c t}\right]
$$

The farmers in each market need to form views about future prices of corn and hogs in order to solve the maximum problems (5) and (I). Since future corn and hog prices will depend on future state variables in each market, including the capital stocks in each market, farmers in each market need to form a view about the laws of motion of the marketwide stocks of capital in both markets. We assume that farmers' views about these laws of motion are correct. It will turn out that the laws of motion for the market-wide capital stocks in the two industries will have the forms

$$
\begin{aligned}
& K_{c t+I}=H_{0}+E_{W}^{c}(I) W_{t}^{c}+E_{w}^{h}(I) W_{t}^{h}+H_{D}^{c}(I) D_{t}^{c} \\
& +\mathrm{H}_{\mathrm{D}}^{\mathrm{h}}(\mathrm{I}) \mathrm{D}_{t}^{\mathrm{h}}+\mathrm{H}_{\varepsilon}^{\mathrm{c}}(\mathrm{I}) \varepsilon_{c t}+\mathrm{H}_{\varepsilon}^{\mathrm{h}}(\mathrm{L}) \varepsilon_{h t} \\
& +\mathrm{H}_{u}^{c}(\mathrm{I}) \mathrm{u}_{c t}+\mathrm{H}_{\mathrm{u}}^{\mathrm{h}}(\mathrm{I}) \mathrm{u}_{h t}+\mathrm{H}_{1}^{c_{\mathrm{C}}} \mathrm{K}_{c t}+\mathrm{H}_{1}^{\mathrm{h}} \mathrm{K}_{h t} \\
& K_{h t+1}=G_{0}+G_{w}^{c}(L) w_{t}^{c}+G_{w}^{h}(I) w_{t}^{h}+G_{D}^{c}(L) D_{t}^{c} \\
& +G_{D}^{h}(I) D_{t}^{h}+G_{\varepsilon}^{c}(I) \varepsilon_{c t}+G_{\varepsilon}^{h}(I) \varepsilon_{h t} \\
& +G_{u}^{c}(I) u_{c t}+G_{u}^{h}(L) u_{h t}+G_{I}^{c} K_{c t}+G_{I}^{h} R_{h t}
\end{aligned}
$$

where $H_{0}, B_{1}^{c}, H_{1}^{h}, G_{0}, G_{1}^{c}, G_{1}^{h}$ are scalars and where 
$H_{w}^{c}(I)$ and $G_{w}^{c}(I)$ are $r_{w}^{c}-1$ order polynomials in $I$. $H_{w}^{h}(L)$ and $G_{w}^{h}(L)$ are $x_{w}^{h}-I$ order polynomials in $L$. $H_{D}^{C}(I)$ and $G_{D}^{C}(I)$ are $r_{D}^{C}-1$ order polynomials in $I$. (2.18) $H_{D}^{h}(L)$ and $G_{D}^{h}(L)$ are $I_{D}^{h}-1$ order polynomials in $I$. $H_{\varepsilon}^{c}(L)$ and $G_{\varepsilon}^{c}(L)$ are $I_{\varepsilon}^{c}-I$ order polynomials in $L$. $H_{\varepsilon}^{h}(I)$ and $G_{\varepsilon}^{h}(L)$ are $I_{\varepsilon}^{h}-1$ order polynomials in $L$. $H_{u}^{c}(I)$ and $G_{u}^{c}(L)$ are $r_{u}^{c}-I$ order polynomials in $L$. $H_{u}^{h}(I)$ and $G_{u}^{h}(I)$ are $r_{u}^{h}-1$ order polynomials in $I$.

تici. of the li(I) and $G(L)$ polynomials is conformable in dimension with the process it premultiplies. Equations (16) and (17) describe famers' perceptions of the laws of motion for $R_{c}$ and $K_{h}$.

The important thing to notice about (16) and (17) is that any variable that appears on the right hand side of one appears on the right side of the other. Thus, the state variables are asserted to be identical for the two industries" aggregate capital stocks. That (16) and (17) embody the correct choices of state variables will now becone evident, as we express the optimum problems of the representative firm in each industry as completely stated dynamic optimization problems. That is; (16) and (17) will turn out to have the correct right hand side variables in the sense that if firms' perceptions of the laws of motion for $K_{c}$ and $k_{h}$ are (16) and (17), respectively, then Eirms' optimizing behavior will imply actual laws of motion for $K_{c}$ and $K_{h}$, respectively, of the same functional forms as assumed for those perceptions. 
$-51-$

From (6) we have that $\mathrm{H}_{t}=(1+\phi) \mathrm{K}_{\mathrm{ht}}-\mathrm{K}_{\mathrm{ht+1}}+\varepsilon_{h t}$. Substituting this into the demand schedule for hogs gives,

$$
P_{h t}=A_{0}-A_{1}\left((1+\phi) R_{h t}-R_{h t+1}\right)+A_{2} D_{1 t}^{h}+u_{h t}-A_{1} \varepsilon_{h t}
$$

Substituting (19) and (15) into (I) and (5) gives the following criterion functions for representative hog farmers and corn farmers, respectively:

$$
E_{0} \sum_{t=0}^{\infty} \beta^{t}\left\{\left[A_{0}-A_{1}\left((1+\phi) K_{h t}-K_{h t+1}\right)+A_{2} D_{1 t}^{h}+u_{h t}-A_{1} \varepsilon_{h t}\right]\right.
$$

(2.21)

$$
\begin{gathered}
E_{0} \sum_{t=0}^{\infty} B^{t}\left\{B_{1}^{-1}\left(\gamma K_{b t}+u_{c t}+B_{0}+B_{2} D_{1 t}^{c}-f R_{c t}-\varepsilon_{c t}\right) f k_{c t}\right. \\
\left.-w_{t}^{c_{k} k_{c t}}-\frac{d}{2}\left(k_{c t+1}-k_{c t}\right)^{2}\right\}
\end{gathered}
$$

The maximization of (20) and (21) each takes place subject to the known laws of motion

$(2.4)$

$$
\delta_{w}^{c}(L) w_{t}^{c}=v_{w t}^{c}
$$

$$
\delta_{w}^{h}(I) w_{t}^{h}=v_{w t}^{b}
$$

$(2.10)$

$$
\delta_{u}^{h}(I) u_{n t}=v_{u t}^{h}
$$

$$
\delta_{u}^{c}(I) u_{c t}=v_{u t}^{c}
$$

(2.14)

$$
\delta_{D}^{c}(L) D_{t}^{c}=V_{D t}^{C}
$$

$$
\delta_{\varepsilon}^{c}(L) \varepsilon_{c t}=\nabla_{\varepsilon t}^{c}
$$

(2.7)

$$
\delta_{\varepsilon}^{h}(L) \varepsilon_{h t}=V_{\varepsilon t}^{h}
$$




$$
\begin{aligned}
& R_{c t+I}=H_{0}+H_{w}^{c}(I) W_{t}^{c}+H_{w}^{h}(L) W_{t}^{h}+H_{D}^{c}(L) D_{t}^{c} \\
& +\mathrm{H}_{\mathrm{D}}^{\mathrm{h}}(\mathrm{I}) \mathrm{D}_{t}^{\mathrm{h}}+\mathrm{E}_{\varepsilon}^{\mathrm{c}}(\mathrm{I}) \varepsilon_{c t}+\mathrm{H}_{\varepsilon}^{\mathrm{h}}(\mathrm{I}) \varepsilon_{\mathrm{ht}} \\
& +E_{u}^{c}(L) u_{c t}+E_{u}^{h}(L) u_{h t}+H_{1}^{c} K_{c t}+H_{1}^{h} K_{h t} \\
& k_{n t+1}=G_{0}+G_{w}^{c}(I) w_{t}^{c}+G_{w}^{h}(I) w_{t}^{h}+G_{D}^{c}(L) D_{t}^{c} \\
& +G_{D}^{h}(I) D_{t}^{h}+G_{\varepsilon}^{c}(I) \varepsilon_{c t}+G_{\varepsilon}^{h}(I) \varepsilon_{h t} \\
& +G_{u}^{c}(I) u_{c t}+G_{u}^{h}(I) u_{h t}+G_{I}^{c} K_{c t}+G_{I}^{h} K_{h t}
\end{aligned}
$$

The optimization for the representative firm in each industry is carried out subject to the information set at time $t, 47$

$$
\begin{aligned}
& \left\{R_{h t}, R_{c t}, w_{t}^{h}, w_{t-1}^{h}, \ldots, w_{t-r_{w}^{h}}^{h}+1, D_{t}^{h}, \ldots, D_{t-r_{D}^{h}}^{h}+1\right. \text {, } \\
& \varepsilon_{t}^{h}, \ldots, \varepsilon_{t-r}^{h} \frac{h+I}{\varepsilon}, u_{h t}, \ldots, u_{h t-r_{u}}^{h_{t}}, w_{t}^{c}, \ldots, w_{t-r_{w}^{c}}^{c}+1 \text {, } \\
& \left.D_{t}^{c}, \ldots, D_{t-r_{D}^{c} c_{1}}^{c}, \varepsilon_{c t}, \ldots, \varepsilon_{c t-I_{E}+1}^{c}, u_{c t}, \ldots, u_{c t-r_{u}^{c}+1}^{c}\right\}
\end{aligned}
$$

In adition, at time $t$ the firm knows its own currentstock of capital $k_{c t}$ or $k_{h t}$, as it chooses $k_{c t+I}$ or $k_{h t+I}$.

The solutions to the problems of the constrained maximization of (20) and (21) are a pair of linear contingency plans of the form

$$
\begin{aligned}
k_{h t+1} & =g_{0}+g_{w}^{c}(I) w_{t}^{c}+g_{w}^{h}(I) w_{t}^{h}+g_{D}^{c}(I) D_{t}^{c} \\
& +g_{D}^{h}(I) D_{t}^{h}+g_{\varepsilon}^{c}(I) \varepsilon_{c t}+g_{\varepsilon}^{h}(I) \varepsilon_{h t} \\
& +g_{u}^{c}(I) u_{c t}+g_{u}^{h}(I) u_{h t}+g_{I}^{c} K_{c t}+g_{1}^{h} h_{h t} \\
& +g_{2}^{h} k_{h t}
\end{aligned}
$$




$$
\begin{aligned}
k_{c t+1} & =h_{0}+h_{w}^{c}(I) w_{t}^{c}+h_{w}^{h}(I) w_{t}^{h}+h_{D}^{c}(I) D_{t}^{c} \\
& +h_{D}^{h}(I) D_{t}^{h}+h_{\varepsilon}^{c}(I) \varepsilon_{c t}+h_{\varepsilon}^{h}(I) \varepsilon_{h t} \\
& +h_{u}^{c}(I) u_{c t}+h_{u}^{h}(L) u_{h t}+h_{1}^{c} k_{c t}+h_{I}^{h} k_{h t} \\
& +h_{2}^{c} k_{c t}
\end{aligned}
$$

where $h_{2}^{c}$ and $g_{2}^{h}$ are scalars and the remaining constants and polynomials in $I$ are of the same dimensions and orders as the corresponding capital lettered quantities in (16) and (17), as defined in (18).

Multiplying (22) by $I$ and (23) by $m$ gives

$$
\begin{aligned}
& K_{h t+1}=n g_{0}+n g_{w}^{c}(t) w_{t}^{c}+n g_{w}^{h}(I) w_{t}^{h}+n g_{D}^{c}(I) D_{t}^{c} \\
& +n g_{D}^{h}(I) D_{t}^{h}+n_{\varepsilon}^{c}(I) \varepsilon_{c t}+n g_{\varepsilon}^{h}(I) \varepsilon_{h t} \\
& +2 g_{u}^{c}(I) u_{c t}+n g_{u}^{h}(I) u_{h t} \\
& n g_{1}^{c} k_{c t}+\left(n g_{1}^{h}+g_{2}^{h}\right) K_{h t} \\
& K_{c t+1}=\operatorname{mh}_{0}+\operatorname{mh}_{w}^{c}(L) w_{t}^{c}+\operatorname{mh}_{w}^{h}(I) w_{t}^{h}+\operatorname{mh}_{D}^{c}(I) D_{t}^{c} \\
& +\operatorname{mh}_{D}^{h}(L) D_{t}^{h}+\operatorname{mh}_{\varepsilon}^{c}(L) \varepsilon_{c t}+m_{\varepsilon}^{h}(I) \varepsilon_{h t} \\
& +m_{u}^{c}(I) u_{c t}+\operatorname{mh}_{u}^{h}(L) u_{h t}+\min _{1}^{h} K_{h t} \\
& +\left(m_{1}^{c}+h_{2}^{c}\right) k_{c t}
\end{aligned}
$$


Equations (24) and (25) are the actual laws of motion for $k_{h t+I}$ and $\mathrm{K}_{\mathrm{ct+1}}$, respectively, that correspond to the percelved laws of motion (17) and (16), respectively. A rational expectations equilibrium is defined as a pair of schedules (16) and (25) which are Identically equal, and a pair of schedules (17) and (24) which are identically equal. This amounts to equating the perceived and actual laws of motion.

Inspection of the criterion functions (20) and (21) and the constraints $(4),(8),(10),(1 I),(13),(14),(3)$, and (7) will convince the reader that the correct state variables have been included in our "guesses" about the forms of the laws of motion (16) and (17) for the aggregate capital stocks $K_{h}$ and $K_{c} \cdot$ The correct principle for the sclection of these state variables is this: any statc variuides that apear either in the objective functions (20) and (21) or in the constraints $(4),(8),(10),(11),(13),(14),(3)$, and (7) at time $t+1$, belong in the laws of motion for the aggregate capital stocks of both industries.

Having defined a rational expectations equilibrium for the model, I now turn to describe how the equilibrium can be calculated via the method corresponding to that used by Iucas and Prescott [37]. As in section 1 , the idea is to "discover" a fictitious social planning problem that the equilibrium implicitly solves. First, notice that since the flow demand curve for hogs is $P_{h t}=A_{0}-A_{1} H_{t}+A_{2} D_{1 t}^{h}+u_{h t}$, the area under the demand curve for hogs is

$$
\begin{aligned}
& \int_{0}^{\mathrm{H}_{t}}\left(A_{0}-A_{1} x+A_{2} D_{1 t}^{h}+u_{h t}\right) d x \\
& =A_{0} H_{t}-\frac{A_{1}}{2} H_{t}^{2}+E_{t} A_{2} D_{1 t}^{h}+H_{t} L_{h t}
\end{aligned}
$$




$$
\begin{aligned}
= & {\left[(1+\phi) k_{h t}-K_{h t+1}+\varepsilon_{h t}\right]\left[A_{0}+A_{2} D_{1 t}^{h}+u_{h t}-\frac{A_{1}}{2}\left((I+\phi) k_{h t}-\right.\right.} \\
& \left.\left.-k_{h t+1}+\varepsilon_{h t}\right)\right]
\end{aligned}
$$

Since the demand curve for final consumption of corn is $P_{c t}=B_{1}^{-1}\left[B_{0}\right.$ $\left.+B_{2} D_{1 t}^{C}+u_{c t}-C_{c t}\right]$, the area under the demand curve for final consumption of corn is

$$
\begin{aligned}
& \delta_{0}^{C} c t B_{1}^{-1}\left[B_{0}+B_{2} D_{1 t}^{C}+u_{c t}-x\right] d x= \\
& B_{0} B_{I}^{-1} C_{c t}+B_{I}^{-I} C_{c t} B_{2} D_{1 t}^{C}+B_{1}^{-1} u_{c t} C_{c t}-\left(2 B_{1}\right)^{-1} C_{c t}^{2}
\end{aligned}
$$

Substituting for $C_{c t}$ from the equilibrium condition $C_{c t}=f K_{c t}+\varepsilon_{c t}-\gamma K_{h t}$ gives the following formula for the area under the demand curve for the final consumption of corn:

$$
\begin{aligned}
& B_{O^{B}} B_{1}^{-1}\left[f R_{c t}+\varepsilon_{c t}-\gamma K_{h t}\right]+B_{1}^{-I} u_{c t}\left[f R_{c t}+\varepsilon_{c t}-\gamma R_{h t}\right] \\
& \quad-\left(2 B_{1}\right)^{-1}\left[f R_{c t}+\varepsilon_{c t}-\gamma R_{h t}\right]^{2}+B_{I}^{-I}\left[f R_{c t}+\varepsilon_{c t}-\gamma R_{h t} j B_{2} D_{1 t}^{c}\right.
\end{aligned}
$$

Now consider the following fictitious social planning criterion:

(2. 29)

$$
\begin{aligned}
& E_{0} \sum_{t=0}^{\infty} B^{t}\left\{\left\{[ ( 1 + \phi ) R _ { h t } - K _ { h t + 1 } + \varepsilon _ { h t } ] \left[A_{0}+A_{2} D_{1 t}^{h}+u_{h t}\right.\right.\right. \\
& \left.\left.-\frac{A_{1}}{2}\left((I+\phi) R_{h t}-K_{h t+1}+\varepsilon_{h t}\right)\right]\right\} \\
& +\left\{B_{0} B_{I}^{-1}\left[E K_{c t}+\varepsilon_{c t}-\gamma K_{h t}\right]+B_{I}^{-1} u_{c t}\left[f R_{c t}+\varepsilon_{c t}-\gamma K_{h t}\right]\right. \\
& \left.-\left(2 B_{1}\right)^{-1}\left[f K_{c t}+\varepsilon_{c t}-\gamma R_{h t}\right]^{2}+B_{1}^{-1}\left[f K_{c t}+\varepsilon_{c t}-\gamma K_{h t}\right] B_{2} D_{1 t}^{c}\right\} \\
& -w_{t}^{c} K_{c t}-w_{t}^{h} K_{h t}-\frac{d}{2}-1\left(K_{c t+1}-K_{c t}\right)^{2} \\
& \left.-\frac{e}{2} a^{-1}\left(k_{h t+1}-k_{h t}\right)^{2}\right\}
\end{aligned}
$$


Consider the maximization of (29), assumed to take place subject to the laws of motion $4,8,10,11,13,14,3$, and 7 . The information set is at time $t$ consists of observations on $K_{h}, K_{c}, \varepsilon_{c}, \varepsilon_{h}, u_{c}, u_{h}, W^{c}$, $W^{h}, D^{c}, D^{h}$ dated $t$ and earlier. At time $t$, the fictitious planner is assumed to set $k_{h t+1}$ and $k_{c t+1}$ as linear functions of the variables in the information set at $t$. The reader can verify that these linear contingency plans will be of precisely the same linear forms as the laws of motion (16) and (17) that are the laws of motion for $K_{c}$ and $K_{h}$ in the rational expectations equilibrium. Furthermore, by a straightforward argument, it can be established directly that the laws of motion for $K_{c}$ and $K_{h}$ that maximize the social planning criterion (29) are precisely the unique laws of motion for the rational expectations equilibrium. 48 !

The problem of maximizing the fictitious social planning criterion (29) subject to the constraints stated above is known in general to have a solution in which all the relevant histories of the state variables $\left\{K_{h}, K_{c}, \varepsilon_{c}, \varepsilon_{h}, u_{c}, u_{h}, W^{c}, W^{h}, D^{c}, D^{h}\right\}$ appear in the optimal law of motion for both $k_{c}$ and $k_{h}$. Computationally efficient methods for obtaining solutions for a general class of "interrelated factor demand" problems, of which (29) is a special case, have been extensively described by Hansen and Sargent [22].

By a series of manipulations wich parallel those used in section 2, it is possible to move from the laws of motion (16) and (17) for the aggregate capital stocks to dynamic flow supply curves for the corn and hog industries. These dynamic supply curves take the form 


$$
\begin{aligned}
c_{t+1} & =s_{0}+s_{w}^{c}(I) w_{t}^{c}+s_{w}^{h}(L) w_{t}^{h}+s_{D}^{c}(I) D_{t}^{c} \\
& +s_{D}^{h}(I) D_{t}^{h}+s_{\varepsilon}^{c}(I) \varepsilon_{c t}+s_{\varepsilon}^{h}(I) \varepsilon_{h t} \\
& +s_{p}^{c}(L) p_{c t}+s_{p}^{h}(L) p_{h t}+s_{I}^{c} k_{c t}+s_{1}^{h} k_{h t}
\end{aligned}
$$

and

$$
\begin{aligned}
H_{t} & =\sigma_{0}+\sigma_{w}^{c}(L) w_{t}^{c}+\sigma_{w}^{h}(I) w_{t}^{h}+\sigma_{D}^{c}(L) D_{t}^{c} \\
& +\sigma_{D}^{h}(L) D_{t}^{h}+\sigma_{\varepsilon}^{c}(L) \varepsilon_{c t}+\sigma_{\varepsilon}^{h}(I) \varepsilon_{h t} \\
& +\sigma_{p}^{c}(L) p_{c t}+\sigma_{p}^{h}(L) p_{h t}+\sigma_{I}^{c} K_{c t}+\sigma_{I}^{h} R_{h t}
\end{aligned}
$$

In (30) and (3I) all polynomials in the lag operator is are comparabie in dimension and order with the corresponding polynomials that appear in (16) and (17), respectively. The point to be emphasized is that each of the dynamic supply curves (30) and (31) inherits as arguments all of the random variables that appear as demand shifters in the flow demand curves for both comodities.

As in the development in section 1, equations (30) and (3I) are relationships that are exact linear functions of the variables in the information sets of private agents. They can be converted to equations that contain what are random errors from the viewpoint of the econometrician by one of the devices described in section 1. For example, we might assume that the econometrician has data on all of the variables on the right sides of $(30)$ and (31), except for current and past values of the shocks in the production relations, $\varepsilon_{c t}$ and $\varepsilon_{\text {ht }}$. inder this interpretation, the distributed lags in $\varepsilon_{c t}$ and $\varepsilon_{h t}$ become the error terms from the econometrician's perspective. 
It is evident from (30) and (3I) that the dynamic economic theory that we are using subverts the usual identification conditions of the exclusion variety. Because of the appearance of all of the state variables in the dynamic supply curves (30) and (31), the supply schedules for hogs and corn are underidentified according to the usual order condition. However, as in section 1, the dynamic theory from which these curves are derived furnishes an extensive set of restrictions between the parameters of $(30)$ and (3I) and the parameters of (4), (8), (10), (11), (13), (14), (3) and (7). These latter parameters are the parameters of the Markov laws for the driving variables.

Although the model of this section admittedy embodies oversimplified technologies, it could readily be extended to incorporate much more "realistic" technologies for the corn and hog industries, even while staying within the

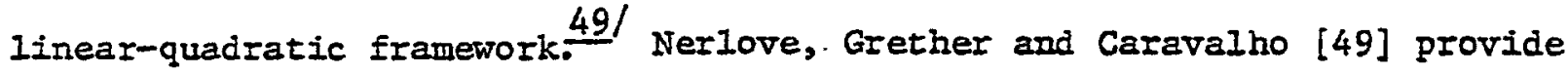
useful indications about how this might be done. Such generalizations can be accomplished at the cost of increases in the number of "state" variables required, but involve no genuine analytical complications beyond those encountered in our corn-hog model. Increasing the number of factors of production in each industry can also be accomplished in a conceptually straightforward manner. Hansen and Sargent [22] have devoted substantial effort to the development of fast methods of computing linear rational expectations equilibria for a wide class of models. The use of these methods will make it practical to construct models of interrelated industries with state vectors of at least moderate dimension.

The Iucas-Prescott example of section 1 and the corn-hog example illustrate a key principle: laws of motion for the endogenous state variables of one industry will generally be functions of all of the state variables characterizing the industries with which it interacts. 
The analyst will often face a hard practical decision about which dynamics he takes as given from outside the model. To illustrate this further, suppose that one of the shifters $D_{1 t}^{C}$ in the demand schedule for corn is the price of wheat, and that the price of corn is also an argument in the demand schedule for wheat. It is then easy to imagine a rational expectations equilibrium model of the corn, hog, and wheat markets. The general point is that a rational expectations equilibrium of industries that use each others outputs as inputs is technically equivalent with the solution of an interrelated factor demand problem in which the laws of motion for states characterizing each one of the industries dynamically interact in interesting ways with the states of all the other industries. Thus, the internal logic of these models tends to propel the analyst toward an even more extended general equilibrium formulation. In any given application, the researcher will have to choose what laws of motion he takes as given from outside the model, for the purposes of the analysis at hand. As our examples indicate, the choice made will influence substantially the definition of equilibrium to be employed.

Superficially, the corn-hog model of this section may seem very much more complicated and difficult to estimate than the Lucas-Prescott example of section 1. However, to some extent this impression is illusory, as the number of free parameters of the model of this section is roughly of the order of magnitude of twice the number for the lucasPrescott example. The lag distributions in (2.24) and (2.25) turn out to be highly restricted by the theory. Hansen and Sargent [ ] have described formulas for describing these restrictions in a way that is convenient both for analysis and estimation. As a result of such research, it seems feasible to estimate models with sizable state-spaces and complicated interrelationships across industries. 
The theoretical and econometric tractability of dynamic systems with large state spaces is the chief virtue of the linear-quadratic setups adopted in this paper. These linear-quadratic setups admittedly sacrifice generality vis-a-vis the methods used by Lucas-Prescott [ ] or Sargent [ ]'in terms of admissible functional forms for objectives and constraints, but for practical applications they permit greater generality vis-a-vis those same alternatives in the sense of easily accomodating high-order serial dependence in the "forcing functions". A major goal of recent research by Hansen and Sargent [ ] and Taylor [ ] is to extend the limits of the dimension of models that can be analyzed and estimated by the above methods. 


\section{Conclusions}

Re-making dynamic econometric practice so that it is consistent with the principle that agents' constraints influence their behavior is a task that is far from finished. Further, properly allowing for the implications of the principle will surely require abandoning many presently received ways of interpreting data. A variety of setups can be imagined that are consistent with the principle. For example, a variety of variations of the setups of this paper can be imagined in which agents optimize, but have smaller information sets than have been attributed to them here. Also, information discrepancies across classes of agents can be assumed. In many such cases, endogenous variables such as prices will play an important role in conveying information to agents. In models with dynamics as complicated as those of our examples, these variations introduce substantial analytical difficulties. To date there is very little work which investigates the econometric implications of . such complications to setups like ours. With or without these complications, building a dynamic econometrics that is consistent with our simple principle from economic theory is a challenging task. It is sure to require substantial changes in the ways that applied economists interpret economic time series. 
1. Anderson, B.D.O., and J.O.B. Moore, Optimal Filtering, Prentice Hall, Englewood Cliffs, New Jersey, 1979.

2. Arzac, E.R. and Maurice Wilkinson, "Stabilization Policies for United States Feed Grain and Livestock Markets", Journal of Economic Dynamics and Control, Vol. 1, No. 1, February, 1979, pp. 39-58.

3. Bertsekas, Dimitri P., "Dynamic Programming and Stochastic Cortrol", Academic Press, New York, 1976.

4. Blackwe11, David, "Discounted Dynamic Programming," Annals of Mathematical Statistics 36,1965 , pp. 226-35.

5. Blanco, Herminio, "Investment Under Uncertainty: An Empirical Analysis", Ph.D. dissertation, University of Chicago, 1978.

6. Chow, Gregory, "Multiperiod Predictions from Stochastic Difference Equations b, Bayesian Methods", Econometrica, 41, Jamary 1973, pp. 109-118.

7. Analysis and Control of Dynamic Economic Systems, Wiley New York, 1975.

8. Craine, Roger, "Investment, Adjustment Costs, and Uncertainty", International Economic Review, October 1975.

9. Crawford, Robert G., "An Empirical Investigation of a Dynamic Model of Labor Turnover in U.S. Manufacturing Industries", CarnegieMellon University, Ph.D. Thesis, 1975.

10. Fisher, Franklin M., The Identification Problem in Econometrics, McGraw-Hil1, New York, 1966.

11. Friedman, Milton, "The Methodology of Positive Economics", in Milton Friedman Essays in Positive Economics, Chicago, University of Chicago Press, 1953.

12. A Theory of the Consumption Function, Princeton, N.J., Princeton University Press, 1957.

13. Friedman, Benjamin, "Discussion", in After the Phillips Curve: Persistence of High Inflation and High Unemployment, Federal Reserve Bank of Boston, Conference Volume 19, 1979.

14. Friedman, Benjamin, "Optimal Expectations and the Extreme Information Assumptions of "Rational Expectations" Macromodels", Journal of Monetar y Economics, Vol. 5, No.1, January 1979.

15. Futia, Car1, "Rational Expectations in Speculative Markets", Manuscript, Bell Telephone Laboratories, 1979.

16. Granger, C.W.J., "Investigating Causal Relations by Econometric Models and Cross-spectral Methods", Econometrica, 37, 1969, pp. 424-438. 
17. Graves, R., and I. Telser, "Functional Analysis in Mathematical Economics", University of Chicago Press, Chicago, 1971.

18. Geweke, John, "Wage and Price Dynamics in U.S. Manufacturing", in C.A. Sims, editor, New Methods in Business Cycle Research: Proceedings From a Conference, Federal Reserve Bank of Minneapolis, 1977.

19. Gordon, Donald and A.G. Hynes, "On the Theory of Price Dynamics", in E.S. Phelps, et. al., Microeconomic Foundations of Employment and Inflation Theory, New York, Norton, 1970.

20. Hansen, L. P., "Large Sample Properties of Genrealized Method of Moments Estimators"' manuscript, 1979.

21. Hansen, L. P., and T.J. Sargent, "A Note on Wiener-Kolmogorov Prediction Formulas for Rational Expectations Models", manuscript, 1979.

22. _Linear Rational Expectations Models for Dynamically Interrelated Variables", in R.E. Lucas, Jr., and T.J. Sargent, eds., Rational Expectations and Econometric Practice, University of Minnesota Press, Minneapolis, 1980.

23. "Formulating and Estimating Dynamic Linear Rational Expectations Models", forthcoming in Journal of Economic Dynamics and Control, 1980.

24. Holt, C., F. Modigliani, T.F. Muth, and H.A. Simon, "Planning Production, Inventories and Work Force", Prentice-Hall, Englewood Cliffs, 1960.

25. Huntzinger, R. La Var, "Market Analysis with Rational Expectations: Theory and Estimation", Journal of Econometrics, 10, 1979, pp. 127145 .

26. Kareken, John A., T. Mnench, and N. Wallace, "Optimal Open Market Strategy The Use of Information Variables", American Economic Review, 1973,

27. Kennan, J., "The Estimation of Partial Adjustment Models with Rational Expectations", Econometrica, forthcoming.

28. Kushner, Harold, "Introduction to Stochastic Control", Holt, Rinehart, and Winston, New York, 1971.

29. Kwakernaak, H., and R. Sivan, "Linear Optimal Control Systems", Wiley, New York, 1972.

30. Kydland, Finn and Edward C. Prescott, "Rules Rather than Discretion: The Inconsistency of Optimal Plans", Journal of Political Economy, 85, 3, June 1977: 473-493.

31. Leamer, Edward E., "A Class of Informative Priors and Distributed Lag Analysis", Econometrica, 40, 1972, PP. 1059-1081.

32. Specification Searches: Ad Hoc Inference with Nonexperimental Data, Wiley, New York, 1979. 
33. Lucas, R. E., Jr., "Econometric Testing of the Natural Rate Hypothesis", in Otto Eckstein, ed., The Econometrics of Price Determination Conference, Board of Governors of the Federal Reserve System, Washington, D.C., 1972, pp. 50-59.

34. "_ "Econometric Policy Evaluation: A Crftique", in K. Brunner and A. H. Meltzer, eds., The Phillips Curve and Labor Markets, Carnegle-Rochester Conferences on Public Policy I, North Holland, Amsterdam, 1976.

35. "An Equilibrium Model of the Business Cycle", Joural of Political Economy, December 1975.

36. __ "Asset Prices in an Exchange Economy", Econometrica, I968.

37. Lucas, R. E., Jr., and E. Prescott, "Investment Under Uncertainty", Econometrica, 39, 1971, pp. 659-681.

38. Lucas, R. E., Jr., and T. J. Sargent, "After Keynesian Macroeconomics", in After the Phillips Curve: Persistence of High Inflation and High Unemployment, Federal Reserve Bank of Boston.

39. "Rational Expectations and Econometric Practice", Introductory essay to Rational. Expectations and Econometric Practice, edited by R. E. Iucas, Jr., and T. J. Sargent, University of Minnesota Press, 1980 (forthcoming).

40. Marschak, Jacob, "Econometric Measurements for Policy and Prediction", in Studies in Econometric Method, edited by William Hood and T. C. Koopmans, Cowles Foundation Monograph, No. 14, New Haven, Connecticut, Yale University Press, 1953.

41. Meese, Richard, "Dynamic Factor Demand Schedules for Labor and Capital Under Rational Expectations", manuscript, 1979.

42. Merton, Robert, "Optimum Consumption and Portfollo Rules in a Continuous Time Model", Journal of Economic Theory, 3, 1970, pp. 373-413.

43. Modigliani, Eranco, "The Vunctarict Coutroversy, or Should We Forsake Stabilization Policies?" Amertcan Economic Review, 67, (Harch 1977), pp. 1-19.

44. Mosca, Edoardo and Giovanni Zappa, "Consistency Conditions for the Asymptotic Innovations Representation and an Equivalent Inverse Regulation Problem", IEEE Transactions on Automatic Control, VoI. AC-24, No. 3, June 1979, pp. 501-503.

45. Mortensen, Dale, "Generalized Costs of Adjustment and Dynamic Factor Demand Theory", Econometrica, 41, 1973, pp. 657-665.

46. Muth, J. F., "Optimal Properties of Exponentially Weighted Forecasts", Journal of the American Statistical Association, 1960, Vol. 55, No. 290, Pp. 299-306.

47. "Rational Expectations and the Theory of Price Movements", Econometrica, Vo1. 29, No. 3, pp. 315-335.

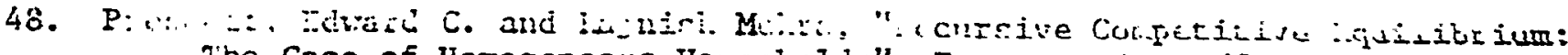
The Case of Homogeneous Households". Econometrica. (farthromina). 
49. Nerlove, Marc, David M. Grether, and Jose L. Carvalho, Analysis of Economic Time Series: A Synthesis, Academic Press, New York, 1979.

50. Nerlove, Marc, "Dlstributed Lags and Unobserved Components in Economic Time Series", in W. Fellner, et. al., Ten Economic Studies in the Tradition of Irving Fisher, John Wiley, New York, 1967 .

51. Sargent, T. J., "The Demand for Money During Hyperinflations Under Rational Expectations: I", International Economic Review, 18, 1977, pp. 59-82.

52. __ "Estimation of Dynamic Labor Demand Schedules Under Rational Expectations", Journal of Political Economy, 86, 1978b, pp. 10091044.

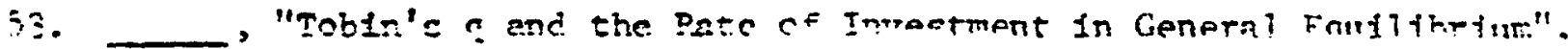
forthconfing in Volume 13 of the Carnegie-Rochester Conference series, ed. by Karl Brunner and Allan Meltzer.

54. Sargent, T. J., Macroeconomic Theory, Academic Press, New York, 1979.

55. Shiller, R., "Rational Expectations and the Structure of Interest Rates", Ph.D. dissertation, Massachusetts Institute of Technology, 1972.

56. __ "A Distributed Lag Estimator Derived From Smoothness Priors", Econometrica, 41, 1973, pp. 775-788.

57. Sims, C. A., "Money. Income and Causality", American Économic Review, 62, 1972, Pp. 540-552.

58. ___ "Macroeconomics and Reality", Econometrica, forthcoming.

59. Taylor, John B., "Output and Price Stability: An International Comparison", manuscript, 1978.

60. __ "Estimation and Control of a Macroeconomic Model with Rational Expectations", Econometrica, forthcoming.

61. Zellner, Arnold, An Introduction to Bayesian Inference in Econometrics, Wiley, New York, 1971. 
Anderson, Paul A., "Rational Expectations Forecasts from Nonrational Models", Journal of Monetary Economics, Vol. 5, No. 1, Jan. 1979, pp. 67-80.

Mishkin, Frederic S., "Simulation Methodology in Macroeconomics: An Innovation Technique", Journal of Political Economy, Vol. 87, No. 4, August 1979, pp. 816-836.

Fischer, Stanley, "Long-Term Contracts, Rational Expectations, and the Optimal Money Supply Rule", Journal of Political Economy, 85, Feb. 1977, pp. 191-205.

Ha1I, Robert E., "The Macroeconomic Impact of Changes in Income Taxes in the Short and Medium Runs", Journal of Political Economy, 86, April 1978, pp. S71-S85.

Phelps, E. S. and John B. Taylor, "Stabilizing Powers of Monetary Policy under Rational Expectations", Journal of Political Economy, 85, Feb. 1977, pp. 163-190.

Sargent, T. J. and Neil Wallace," Rational' Expectations, the Optimal Monetary Instrument, and the Optimal Money SuppIy Rule", Journal of Political Economy, 83, April 1975, pp. $241-254$.

Sargent, Thomas J., "A Note on the Accelerationist Controversy", Journal of Money, Credit, and Banking, Vol. III, No. 3, August 1971, pp. 721-725.

Almon, Shirley, "The Distributed Lag Between Capital Appropriations and Expenditures", Econometrica, Vol. 33, 1965, pp. 178-196.

Koyck, L. M., Distributed Lags and Investment Analysis, North-Holland, Amsterdam.

Cagan, Phillip, "The Monetary Dynamics of Hyperinflation". In Studies in the Quantity Theory of Money (M. Friedman, ed.), Chicago: University of Chicago, 1956, pp. 25-117.

Jorgenson, Dale W., "Rational Distributed Lag Functions", Econometrica, VoI. 34, 1966, Pp. 135-149.

Lucas, R. E., Jr., "Expectations and the Neutrality of Money", Journal of Economic Theory, 4, April 1972, pp. 103-124. 


\section{FOOTNOTES}

1. Examples of work in the general line are Taylor [59, 60], Meese [41], Kennan [27], Crawford [9], Blanco [ 5], Huntzinger [25], Nerlove, Grether and Carvalho [49], Craine [ 8], Geweke [18], Hansen and Sargent [21, 22, 23], and Sargent [51, 52].

2. The papers by Paul Andarson [ ] and Frederick Mishkin [ ] sce... at least partly motivated by this interpretation.

3. The set of Ideas I discuss in this paper has perhaps received most notoriety in the context of macroeconomic examples. In particular, substantial attention has been devoted to the sample economies of Lucas [ ] and Sargent and Wallace [ ] In which those systematic nonneutralities that come from imputing persistently suboptimal expectations to agents were shown to disappear when the hypothesis of rational expectations was imposed on agents. Crudely put, certain classes of systematic monetary policies, in particular those which operate solely via deception, were rendered impotent in the Lucas and Sargent and Wallace examples. Since the publication of these papers, many papers have been published that have described setups in which the choice of systematic policy matters, even when rational expectations prevail. These papers usually invoke a source of nonneutrality not based on deception, of which there are many in standard macroeconomic theory. Papers of this class have often been interpreted as providing a defense of "pre-rational expectations" activist policies along lines that were produced by calculating optimal controls for Reynesian econometric models of the style of the late $1960^{\prime}$ s. In fact, no such defense is implied partly because the methods by which optimal controls for government policy variables are calculated is very different in all rational expectations models from the procedures that were applied to pre-rational expectations models, but also because the 
ways in which econometric estimates are to be constructed for rational expectations models, with or without neutralities, differ substantially Erom the methods applied to the Reynesian models of the 1960's. The main point of the Lucas [ ] and Sargent and Wallace [ ] examples is that substituting the assumption of rational expectations for "adaptive" expectations makes a critical difference for the methods both by which we should evaluate and optimally choose government policies. That same message is present in the papers of Phelps and Taylor [ ], Fischer [ ], and Hall [ ], even if superficially the differences in some qualitative features of the optimal policies under the two assumptions on expectations may have seemed less dramatic than in Sargent and Wallace's example or Lucas's.

4. Using the methods of discounted dynamic programing (e.g. BIackwell [ 4]), theoretical results establishing existence and uniqueness of equilibria and various qualitative features of the equilibria can often be obtained for "weak" or "general" assumptions such as that utility is concave, constraint sets are convex and monotone in shift variables, and so on. Lucas and Prescott [37] and Lucas [36] give interesting illustrations of these methods. These techniques were also used by Sargent [53] to make some genera] observations on interpreting time series correlations between "Tobin's q" variable and the aggregate rate of investment. However, for applied work, it is necessary to be able to calculate equilibria as a function of the free parameters of preferences and constraints, and it is highly desirable if the equilibria can be calculated easily. While for general functional forms, it is in principle possible to calculate equilibria of recursive competitive models using a contraction mapping, in practice sucin methods are presently too expensive to use in empirical work. For this reason, for empirical work it is presently necessary to choose functional forms for which equilibria can be calculated either analytically or "very quickly". Iinear-quadratic 
specifications are one of the few such choices of convenient functional forms available. (Various versions of logarithmic specification are also sometimes tractable, e.g. Merton [42]). A valuable treatment of recursive competitive equilibrium models with general specifications of functional forms is Prescott and Mehra [48].

5. I shall impose the condition that the zeroes of $\delta_{\varepsilon}(z), \delta_{u}(z)$, det $\delta_{D}(z)$ and det $\delta_{w}(z)$ each exceed unity in modulus. Actually, a weaker condition would suffice, namely that the zeroes of these polynomials each exceed $\sqrt{\beta}$ in modulus, where $\beta$ is the discount factor introduced below. These conditions on the zeroes are regularity conditions that assure that the infinite series calculated on page below converge.

6. An $(n \times 1)$ vector white noise $\nabla_{t}^{x}$ is said to be fundamental for an $(n \times 1)$ vector process $x_{t}$ if the vector of one-stepahead linear least squares errors in predicting $x_{t}$ from past $x^{\prime} s$ can be written as a linear combination of the $z$ ccopoc: $i: \because$.

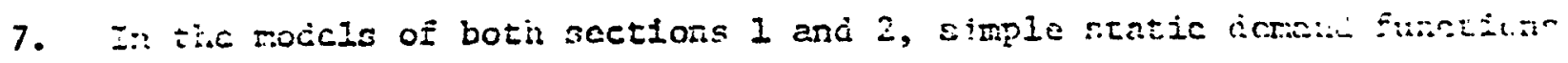
are posited. As a result, all of the interesting dynamics of tile models comes from their supply sides. Specifying a demand schedule with interesting dynamics would complicate the presentation, but not alter the basic messages of our examples. Graves and Telser [17] analyze dynamic optimization problems in which much of the interesting dynamics comes from a demand curve that is specified. Sargent [54, Ch. 16] analyzes a model of the labor market in which the dynamics are influenced by nontrivial dynamic optimization problems solved by botin suppliers and demanders.

8. It would be straightforward to modify this setup to assume that the $\{W, u, \varepsilon, D\}$ processes are each finite order mixed moving average, autoregressive processes. For the details, see Hansen and Sargent [2I]. 
9. These variables completely characterize the "state" vector for the firm's problem. We have in mind that the firm actually has observations on values of $k, k, W, D, \varepsilon$, and $u$ for all dates $t$ and earlier. It turns out that the firm's decisions are optimally a function only of the information set listed in the text.

10. It is assumed that each of $v_{t}^{W}, v_{t}^{u}, v_{t}^{D}$ and $v_{t}^{\varepsilon}$ is orthogonal to the information set $\left\{W_{t-s}, u_{t-s}, D_{t-s}, \varepsilon_{t-s}, s \geq 1\right\}$.

11. This is because we want the stochastic difference equations describing the behavior of the system to be linear, and thereby to be readily susceptible to econometric analysis.

12. That the solution to the problem is of this form follows from Iinear optimal control theory. See Kushner [24, Chapter 9], Bertsekas [ 3, Chapter 3], Sargent [54, Chapter XIV], or Kwakernaak and Sivan [29].

13. For a discussion of the use of lag operators in the present context, see Sargent [54, chapters IX and XIV].

14. In effect, the transversality condition compels us to solve the unstable root forward in this manner.

15. As noted above, we shall want the relevant conditional expectations to be linear. So we shall regard the $E\left(\cdot \mid \Omega_{t}\right)$ that appears in (15) and elsewhere as wide-sense conditional expectations, that is, linear least squares predictors. This amounts to restricting the firm to Iinear decision rules, as desired.

16. Ti.e pazameters $B$ and $n$ also belong in this list of unicriyirs parameters of the model. I shall usually delete these two parameters from subsequent listings of the model's underlying parameters, though they should be understood. In some applications, the analyst may want to specify counterparts of $B$ and $n$ completely a priori, in which case they would not be included among the "free parameters" of the model over which the Iikelihood function or other measure of "fit" 
1j. The following argunent in the text provides a way of "discovering" Lucas and Prescott's [37] method of calculating the ratiunal t:xpectation: equilibrium by formulating a fictitious social planning problem that reproduces the equilibrium. It is worth remarking that kydland and Prescott [30] describe a recursive method of calculating a linear rational expectations equilibrium that is applicable to our problem and is distinct from the Lucas-Prescott method upon which the discussion in the text is based. Kydland and Prescott's method successfully computes the equilibrium even in instances in which the Lucas-Prescott method breaks down. These instances occur, for example, in which there is feedback from the industry-wide aggregate capital stock $K$ to $W$ or $D$, as would occur if lagged $K^{\prime} s$ appeared as states in the Markov law for $W$ or $D$. In such instances, Lucas and Prescott's social planning problem fails to reproduce the rational expectations equilibrium essentially because the fictitious planner takes into account the "externality" that the feedback from $K$ to $h$ or $D$ constitutes.

18. This was emphasized in a more general contcxt by Lucas and Prescott $[30]$.

19. It can also be proved that the transversality condition for (17) imposes the same condition on the solution as does the transversality condition of the representative firm.

20. This follows directly from the observation that if $z_{0}$ is a zero of $\left[1-\left(I+B^{-1}+A_{1} f^{2}\right.\right.$ nd $\left.\left.{ }^{-1}\right) z+B^{-1} z^{2}\right]$, then so is $B z_{0}^{-1}$. 21. Note that the equation (1.19) satusies the first-orjer nectsar; conditions for the optinization problen but gives the "planner" too much information (it is "anticipative" or "nonrealizable"). The correct solution to the problem taking the information set available to the "planner" into account is the solution of the first-order necessary conditions that expresses $k_{t+1}$ as a function oniy of 
information that the planner possesses at time $t$. Such a solution is sald to be "realizable" or "nonanticipative".

22. By expanding the polynomial in $L$, it is possible to stow that

(*) $\frac{I^{-1}\left(I-\delta(\lambda \beta)^{-1} \delta(L)\right)}{1-\lambda \beta L^{-1}}=\delta(\lambda \beta)^{-1}\left[\sum_{j=0}^{I-1}\left(\sum_{k=j+1}^{I}(\lambda \beta)^{k-j-1} \delta_{k}\right) I^{j}\right]$ where $\delta(L)=I-\sum_{j=1}^{I} \delta_{j} L^{j}$. Notice that the polynomial or the left side of (*) Is one sided in nonnegative powers of $I$, iespite the appearance of $I^{-1}$, and that it is a polynomial of order $(I-I)$, as asserted in the text. The formula (*) can be derived by mimicking the procedures used in Eansen and Sargent [23]. The same mathematical techniques used by Hansen and Sargent [23] to derive expressions Iike (21) or (*) were independently utilized by Futia [15] to compute linear rational expectations equilibria. Also, without knowing of Hansen and Sargent's work, John Kennan independently derived formulas similar to (*) in a personal letter to me.

23. From this point of view, it is irrelevant whether Granger causality is consistent with one's notion of what "true" causality is. Christopher Sims [57] has described the relationship of the concept of Granger causality to that of strict econometric exogeneity. That a random process $y$ fail to Granger-cause $x$ is a necessary condition for $x$ to be strictly econometrically exogenous with respect to $y$. For this reason, the concept of Granger causality is also useful in designing specification tests. For a discussion of the relationship between Granger causality and econometric exogeneity in the context of Iinear rational expectations models, see Hansen and Sargent [23]. 
24. Thus Franklin Fisher wrote: "In practice, except for such covariance restrictions [across disturbances in distinct structural equations], restrictions which relate the parameters of one equation to those of one or more others are extremely rare. There is no reason in principle why such cases cannot occur, however, and it may be worthwhile devoting a very short discussion to them." [10, p. 176].

25. By now, this is a routine and uncontroversial definition of an "intervention". Applications of the techniques of optimal control theory to the calculation of macroeconometric and microeconometric policy response functions employ precisely this concept of intervention (see e.g. Chow [6], Taylor [60], Kareken, Muench, and WaIlace [26], and Arzac and Wilkinson [2]-;

26. For example, if it becomes a cartel when before it had been competitive or noncooperative in some way.

27. A technical qualification needs to be added at this point. In order to have a model capable of predicting effects of interventions acting on the $\delta^{\prime} s$, one can sometimes get by without having uniquely identified the parameters $\{A, f, d\}$. What the researcher must identify are the parameters of the characteristic polynomial of the Euler equation (16), namely the paramieters $\phi_{0}, \phi_{1}$ in $\left[B d-\left(d(I+\beta)+A_{1} f^{2} n\right) I+d I^{2}\right]=\left[B \phi_{1}+\phi_{0} I+\phi_{1} I^{2}\right]$ where $\phi_{1}=d$, and $-\phi_{0}=\left(d(I+B)+A_{1} f^{2} n \beta\right)$. The theory assumes that the $\phi_{j}$ 's will be invariant with respect to interventions on the $\delta$ 's. If the researcher can uniquely identify the $\phi_{j}^{\prime} s$, he can proceed with econometric policy evaluation, even if he cannot uniquely identify all of $\left(A_{1}, f\right.$, d). In some setups, the parameters of the characteristic polynomials of the Euler equations are identified even though only an equivalence class of the counterparts of $\left(A_{1}\right.$, $\left.f, d\right)$ 
1s 1dentified. This is enough for econometric policy evaluation to proceed. This problem is discussed by Hansen and Sargent [22]. It is technically related to the "Inverse optimal control" problem (see Mosca and Zappa [44]).

28. This message is at least implicit in the work by lucas and Prescott [37]. Gordon and Hynes [19] made the argument in an informal way. Iucas [34] forcefully brought the message to the attention of macroeconomists.

29. However, some economists continue to argue that existing macroeconometrlc models can be used to predlct the effects of such arbitrary sequences. (See Friedman [13]).

30. See Benjamin Friedman [14] and Franco Modigliani [43].

31. See Anderson and Noore [1]. The Kalman filter provides a model of Bayesian learning about the $\delta^{\prime} s$ where the initial prior and the posteriors are multivariate normal. However, as Lars Hansen points out to me, normal posteriors for the $\delta^{\prime} s$ are inadmissible for dynamic models of the class described here. This is because the dynamic optimization problems we consider may be ill-posed for points in the parameter space of $\delta^{\prime} s$ for which the zeroes of det $\delta(z)$ are less than $\sqrt{6}$ in modulus. Only priors and posterfors that assign zero probability to this region of the parameter space are in general admissible for our problems. This rules out multivariate normal distributions. Taking account of this admissibility constraint severely complicates the task of building a model of optimal learning about the $\delta$ 's.

32. Further, notice that if the decision rules could be calculated in closed form under uncertainty about the $\delta^{\prime} s$, the resulting time series models would have time-varying coefficients and so be non-stationary. Even if calculating the decision rules were a tractable taisk under uncercainty 
about the $\delta^{\prime} s$, the loss of stationarity that it would imply might well be a price that the applied economist would not be prepared to pay even in exchange for the "greater realism" of the learning assumpt10n.

33. This is a consequence of the fact that the representative firm views itself as playing a dynamic "game against nature", and so finds it optimal to use a nonrandom strategy, that is, a strategy that can be expressed as an exact function of its information variables and other state variables.

34. This is a version of the madel of the error term analyzed by Hansen and Sargent $[23 j$ and Sargent [52].

35. hic have assumed that $v_{t}^{c}$ and $v_{t}^{u}$ are the "innovations" or one-stepahead errors in predicting $\varepsilon_{t}$ and $u_{t}$ on the basis of observations on all variables in agents' information set at time $t-1$ (see footnote 6). This implies that $v_{t+1}^{\varepsilon}$ is orthogonal to all variables on the right side of (25). If we assume that $v_{t}^{u}$ is orthogonal to $v_{t}^{\varepsilon}$, it also impiles that $\nabla_{t}^{u}$ is orthogonal to $F_{i}$ Infosir; ti.t $v_{t}^{\mathrm{a}}$ is orthogonal to $D_{1 t}$ amounts to assuming that $D_{1 t}$ is strictly exogenous in (26), which is stronger than the Granger causalfty assumptions already imposed on $D_{1 t}$, namely, that except for lagged $D^{\prime} s$, no other varlables in the model Granger-cause $D_{1 t}$.

36. There is a singular class of exceptions to this statement. In the special case that

$$
\text { (t) } E D_{1 t+j}\left|\left\{D_{t-s}\right\}_{s=0}^{\infty}=E D_{1 t+j}\right|\left\{D_{2 t-s}\right\}_{s=0}^{\infty}
$$

for all $\mathrm{j} \geq 1, \mathrm{D}_{2 t}$ 's will appear in the demand schedule but not In the supply schedule. The condition $(+)$ is usually thought to be exceedingly: unlikely for any economic time series $\left[D_{I t}\right\}$.

37. These remarks about identification should be compared to Milton Friedman's discussion [11] of the conditions needed Eor "supply" and "demand" to provide a useful categorization of the factors 
impinging on price and output. Friedman argued that the categorization was useful to the extent that it effectively sorted forces acting on price and output into mutually exclusive categories.

38. The fact that the demand curve exc1 is some variables that appear in the supply schedule is due to the static specification for the demand curve. This feature of the model would not survive a variety of alterations that might plausibly be used to introduce dynamics into the demand curve. For example, if the demand schedule involved expected future prices as arguments, all variables that help to predict future prices would appear in the econometrically operational expression for current $P_{t}$ that would correspond to (26).

39. This characteristic of identification in rational expectations models has been noted in various contexts by several authors including Iucas [35] and Sims [58].

40. See Hansen and Sargent [23] for a discussion of the details.

41. This restriction was criticized by Iucas [ ] and Sargent [ ] for essentially the same reasons given here.

42. A point related to that raised in footnote 29 is relevant here. Priors and posteriors that assign positive probability to points in regions for which zeroes of det $\delta(z)$ are less than $\sqrt{B}$ in modulus are inadmissible. This is because under such distributions, for some regions in the parameter space with positive probability, the dynamic optimum problems are not well posed. Taking this into account would substantially complicate the analysis since it would involve using mathematically less tractable distributions..

43. This model of the error term was originally proposed by Shiller [55] in a related but somewhat different context. The model was applied in the present context by Hansen and Sargent [23]. Nerlove, Grether and Carvalho [49] also recomend Shiller's model of the error term. 
44. See Harsen and Sargent [23].

45. Again, see Hansen and Sargent [23].

46. Under regularity conditions provided by Hansen [20], the estimators of the underlying paraneters are shown to be consistent, and most efficient within a restricted class of estimators. Hansen's discussion of the conditions for consistency, which also has implications for the conditions for consistency of maximum likelihood estimators, is at this date the key reference on issues of statistical consistency in linear rational expectations models.

47. I assume that each of the innovations

$\left\{v_{w t}^{c}, \nabla_{w t}^{h}, \nabla_{u t}^{h}, \nabla_{D t}^{h}, \nabla_{u t}^{c}, v_{D t}^{c}, \nabla_{\varepsilon t}^{c}, v_{\varepsilon t}^{h}\right\}$

is orthogonal to the information set

$\left\{w_{t-s}^{h}, w_{t-s}^{c}, \frac{1}{t-s}_{t-s}, D_{t-s}^{c}, \varepsilon_{h t-s}, \varepsilon_{c t-s}, u_{h t-s}, u_{c t-s} ; s \geq 1\right\}$.

48. This can be established as follows. First, obtain the Euler equations for the social planning problem of maximizing (29). Next, obtain the Euler equations for the optimum problems (20) and (2I) of the representative hog and corn farmers, respectively. Upon using $K_{h t}=n k_{h t}$ and $K_{c t}=m k_{c t}$ to eliminate $k_{h t}$ and $k_{c t}$ from the representative firms' Euler equations in favor of $K_{h t}$ and $K_{c t}$, it will be noticed that the resulting equations are the Euler equations of the social planning problem. This argument parallels that used in section 1. Furthermore, it can be demonstrated that the transversality conditions of the planning problem and the representative firms' problems also match up. 
49. As I have interpreted the models described in this paper, agents are regarded as using a long list of state variables to forecast future prices. A criticism of this interpretation of the models, which is called to mind by the naming of commodities as "corn" and "hogs", might be that it ignores the existence of futures markets which confront agents with prices at which they can purchase or sell for future delivery. So maybe agents are being modeled as having to forecast too much. In the presence of a sufficiently large set of markets in state contingent futures claims, agents would have to do no forecasting. It would be a more or less standard application of the Arrow-Debreu apparatus to reinterpret the current models as ones in which there is a complete set of Arrow-Debreu contingent claims markets. Lucas and Prescott [ $]$ and Sargent [ pp. 376-7] provide examples of such reinterpretations in related contexts. So there is a limited sense in which the models described here can accomodate futures markets, Iimited because the models seem to explain "too many" such futures markets. 